\title{
A multi-spacecraft survey of magnetic field line draping in the dayside magnetosheath
}

\section{J. Coleman}

British Antarctic Survey, High Cross, Madingley Road, Cambridge, CB3 0ET, UK

Received: 10 January 2003 - Revised: 4 January 2005 - Accepted: 21 January 2005 - Published: 30 March 2005

\begin{abstract}
When the interplanetary magnetic field (IMF) encounters the Earth's magnetosphere, it is compressed and distorted. This distortion is known as draping, and plays an important role in the interaction between the IMF and the geomagnetic field. This paper considers a particular aspect of draping, namely how the orientation of the IMF in a plane perpendicular to the Sun-Earth line (the clock angle) is altered by draping in the magnetosheath close to the dayside magnetopause. The clock angle of the magnetosheath field is commonly estimated from the interplanetary magnetic field (IMF) measured by upstream monitoring spacecraft either by assuming that the draping process does not significantly alter the clock angle ("perfect draping") or that the change in clock angle is reasonably approximated by a gas dynamic model. In this paper, the magnetosheath clock angles measured during 36 crossings of the magnetopause by the Geotail and Interball-Tail spacecraft are compared to the upstream IMF clock angles measured by the Wind spacecraft. Overall, about $30 \%$ of data points exhibit perfect draping within $\pm 10^{\circ}$, and $70 \%$ are within $30^{\circ}$. The differences between the IMF and magnetosheath clock angles are not, in general, well-ordered in any systematic fashion which could be accounted for by hydrodynamic draping. The draping behaviour is asymmetric with respect to the y-component of the IMF, and the form of the draping distribution function is dependent on solar wind pressure. While the average clock angle observed in the magnetosheath does reflect the orientation of the IMF to within $\sim 30^{\circ}$ or less, the assumption that the magnetosheath field direction at any particular region of the magnetopause at any instant is approximately similar to the IMF direction is not justified. This study shows that reconnection models which assume laminar draping are unlikely to accurately reflect the distribution of reconnection sites across the dayside magnetopause.
\end{abstract}

Keywords. Magnetospheric physics (Magnetopause, cusp and boundary layers; Magnetosheath; Solar windmagnetosphere interactions)

Correspondence to: I. J. Coleman

(ijc@bas.ac.uk)

\section{Introduction}

The solar wind carries the interplanetary magnetic field (IMF) towards the Earth. As the solar wind flow is deflected around the Earth's magnetic field, its orientation changes, as the field is frozen into the solar wind plasma. This phenomenon is known as draping.

The relative orientations of the magnetic fields in the magnetosheath and the magnetosphere may be crucially important in determining the location and rate of magnetic reconnection, the most important process by which the solar wind couples to the Earth system (Dungey, 1961). In the Sonnerup (1974) model, the reconnection rate depends on the magnetic shear. In the antiparallel reconnection hypothesis, reconnection at the dayside magnetopause occurs where the shear angle is close to $180^{\circ}$ (Crooker, 1979).

Models of draping include the gasdynamic model of Spreiter et al. (1966), the analytic magnetosheath model of Kobel and Flückiger (1994), and simplest of all the perfect draping approximation. Luhmann et al. (1984) used a gas-dynamic draping approximation to model the antiparallel locations on the magnetopause for a range of IMF orientations. The Kobel and Flückiger model has been used by Cooling et al. (2001) in calculating the motion of reconnected flux tubes along the magnetopause. A perfect draping approximation was used by Coleman et al. $(2000,2001)$ and Rodger et al. (2000) to model the location of antiparallel regions on the dayside magnetopause and their ionospheric footprints. All of these draping models give rise to qualitatively similar antiparallel regions: For purely southward IMF, a single antiparallel region extends along the equator and across much of the dayside, if a y-component is added to the IMF it results in two antiparallel regions which move to higher latitudes as the clock angle increases, and northward IMF gives rise to small antiparallel regions at the northern and southern lobes. The quantitative differences between the models are smallest near the subsolar point, and increase smoothly towards the flank regions, but all models agree on the general shape and approximate location of antiparallel reconnection sites.

Single-spacecraft studies of the magnetosheath field have been made by Kaymaz (1998), who compared IMP-8 
observations approximately $30 R_{E}$ downtail of the Earth with gasdynamic model predictions, and Dunlop et al. (1999), who studied the properties of the low-latitude dawnside flanks of the magnetopause in detail with the Equator-S spacecraft. The former paper finds that the field orientation in the $\mathrm{y}-\mathrm{z}$ plane is consistent with the magnetohydrodynamic (MHD) model for southward IMF, and with both the gas dynamic and MHD models for northward IMF, except in the immediate vicinity of the magnetopause boundary, where turbulent structures are observed. This turbulence near the magnetopause was also reported in earlier analyses of the same data set (Kaymaz et al., 1992 and 1995). The paper by Dunlop et al. (1999) is primarily concerned with the shape of the magnetopause boundary, but does note that the magnetosheath field appears to be highly draped. Twospacecraft observations, relating the magnetosheath field to the upstream solar wind, have been done for a small number of case studies: Zhang et al. (1996) presented three case studies of combined ISEE-3 and ISEE-2 observations, finding that upstream measurements allowed a reasonably accurate estimate of magnetosheath parameters except in the immediate vicinity of the magnetopause, while Petrinec et al. (1997) studied six Geotail passes through the magnetosheath region downstream of Earth, in conjunction with the corresponding solar wind data from the Wind spacecraft, in order to test an MHD model of the magnetosheath velocity field.

In this paper, magnetic field orientations measured during 36 crossings of the magnetopause, by the Geotail or Interball-Tail (GIT) spacecraft, are compared to the relevant upstream IMF orientations measured by the Wind spacecraft. The aim is to investigate how well, or otherwise, a "perfect draping" model fits the data, to establish the magnitude and character of the angular differences between magnetic field orientations in the IMF and in the magnetosheath, and to investigate how these depend on solar wind conditions and on the magnetopause region where the crossing takes place.

\section{Time series analysis}

The core of this study is the comparison of two time series: the magnetic field orientation measured in the solar wind by Wind, and that measured in the magnetosheath close to the magnetopause by GIT. The magnetic field data used in this paper come from the MFI instrument on Wind (Lepping et al., 1995), the MGF instrument on Geotail (Kokubun et al., 1994), and the MFI instrument on Interball-Tail (Klimov et al., 1997). Plasma data come from the SWE instrument on Wind (Ogilvie et al., 1995), the CPI instrument on Geotail (Frank et al., 1994) and the ELE instrument on Interball-Tail (Sauvaud et al., 1995). Time resolutions are $1 \mathrm{~min}$.

There are two basic steps in analysing any particular magnetopause crossing: identifying the time of the crossing, and calculating the time delay between the crossing measurements and the corresponding upstream solar wind data. A third step becomes necessary when dealing with several independent crossings. In order to take into account the vari- ability of the magnetopause location, the position data of the magnetopause crossing spacecraft is scaled to fit a standard reference magnetopause. This allows data from different crossings, with different magnetopause locations, to be more meaningfully compared. Each of these three steps is described in more detail below.

\subsection{Crossing identification}

The first stage is to determine from orbit plots and a model magnetopause a suitable interval where a crossing is expected (typically a $24 \mathrm{~h}$ interval). The criteria are that the GIT spacecraft orbit must intersect the CDAWeb model magnetopause (http://cdaweb.gsfc.nasa.gov/cdaweb/ moreabout.html) during the interval, that this intersection must be closer to the middle of the interval than to the start or the end, and that the Wind spacecraft must be situated such that its distance from the line between the Sun and the GIT spacecraft is small compared to the distance between Wind and the GIT spacecraft. In cases where the second criterion is not satisfied, the start and end times of the interval are shifted by $6-12 \mathrm{~h}$ in order to bring the crossing time closer to the centre of the interval. This is a precaution to ensure that the initial data set contains all data relevant to the crossing. The third criterion, relating to the distance of Wind from the Sun-GIT line, eliminates those spacecraft configurations in which substantial differences between the solar wind phase front experienced by Wind and that incident on the magnetopause would be most likely. The goal at this stage is simply to identify data intervals within which a suitable crossing is likely to be found. Assessing the data quality and choosing an appropriate section of the data for quantitative analysis are left until a later stage.

For this interval, the magnetic field clock angle at Wind and the GIT spacecraft are calculated from the magnetic field components of each spacecraft. The clock angle is defined as $\arctan \left(B_{y} / B_{z}\right)$, where the magnetic field vector is $\left(B_{x}, B_{y}, B_{z}\right)$ in Cartesian GSM coordinates. The transition parameter for the magnetopause crossing is also calculated, in the manner set out by Hapgood and Bryant (1992). This transition parameter is derived by fitting a cubic curve to the temperature (T) and number density (N) data, with $\log _{10} \mathrm{~N}$ as the independent variable and $\log _{10} \mathrm{~T}$ as the dependent variable. The transition parameter for each data point is then the distance along this curve between an arbitrary origin and the data point in question, normalised such that the parameter varies from 0 in the magnetosheath to 100 in the magnetosphere. The physical basis of the transition parameter is that density and temperature are anticorrelated during a boundary-layer crossing, and Hapgood and Bryant show that it is effective in distinguishing magnetosheath from magnetosphere data.

For Geotail, the transition parameter is calculated from the ion temperature and density; for Interball, from the electron temperature and density. A short study was done, comparing ion data with electron data for intervals where both were 


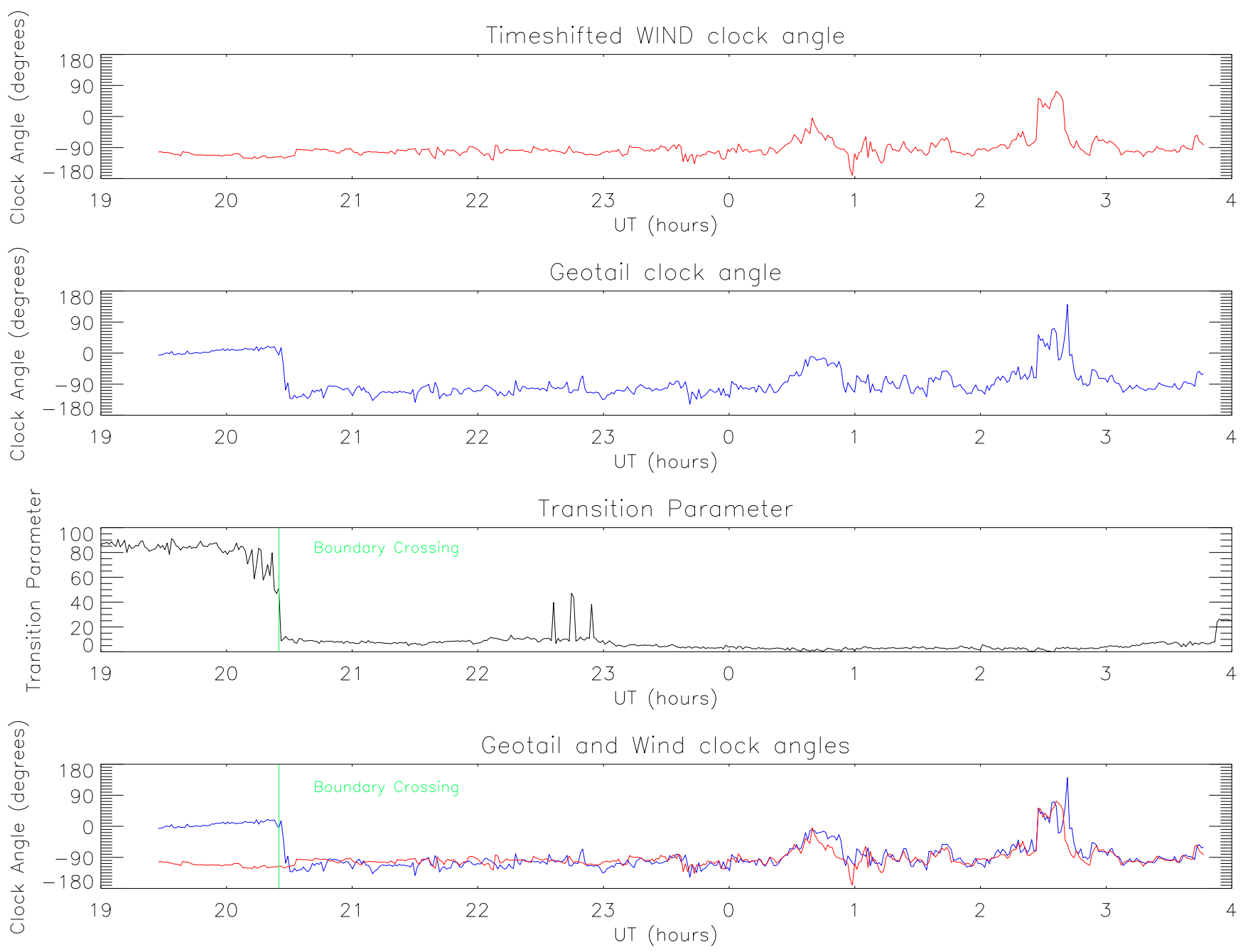

Fig. 1. An example of the magnetopause crossings used in this paper. The upper two panels show the magnetic field clock angles measured by the Wind and Geotail spacecraft; the Wind data have been timeshifted as described in Sect. 2.2. The third panel shows the transition parameter derived from the Geotail data (see Sect. 2.1) and the estimated time of the magnetopause crossing. In the bottom panel, the clock angle data from both spacecraft are overlaid, and the magnetopause crossing time indicated. This data set is from day 118,1999 .

available, showing that ion data gave similar transition parameter results to electron data for Geotail.

Typically, the signature of a magnetopause crossing is a large discontinuity in the transition parameter, coincident with a change in the behaviour of the clock angle measured by the magnetopause-crossing spacecraft. Within the magnetopause, the clock angle varies slowly and is uncorrelated with the upstream IMF direction, whereas in the magnetosheath the clock angle is highly variable and often exhibits gross features (e.g. steps) which can be matched up with similar features in the IMF data. A typical magnetopause crossing is illustrated in the top three bands of Fig. 1, which shows the variation of the clock angle at Wind, and of the clock angle and transition parameter at the GIT spacecraft, respectively, for one of the intervals used in this study. Where a crossing can be clearly identified in the transition parameter and in the comparison between Wind and spacecraft clock angle, the magnetopause boundary is set at that point. Where no clear crossing can be identified, the interval is discarded: this occurred for eight events. In the case of multiple magnetopause crossings, the only data used is from outside the first inbound or last outbound crossing. In general, the discontinuity in the behaviour of the spacecraft clock angle around the time where the transition parameter indicated a crossing was very marked, and allowed the boundary to be set by visual inspection. By comparing the Wind and GIT clock angle data, and by inspecting the transition parameter time series and the GIT orbit data, a time is then chosen when the GIT spacecraft is unambiguously deep into the magnetosheath. The precise time chosen is somewhat arbitrary: this procedure is used simply to cut the size of the data files to be processed. A reduced data interval is then formed, bounded by these two times: data which lies outside this interval is discarded. Typically, the reduced data intervals are several hours in extent. The reduced intervals used in this paper are detailed in Tables 1 and 2. 
Table 1. Magnetopause-crossing intervals from the Interball-Tail spacecraft.

\begin{tabular}{ccccc}
\multicolumn{5}{c}{ Interball-Tail } \\
\hline year & start day & $\begin{array}{c}\text { start time } \\
\text { (UT) }\end{array}$ & end day & $\begin{array}{c}\text { end time } \\
\text { (UT) }\end{array}$ \\
\hline 1998 & 110 & $02: 47$ & 110 & $06 ; 05$ \\
1998 & 117 & $01: 01$ & 117 & $04: 35$ \\
1998 & 120 & $22: 15$ & 120 & $23: 17$ \\
1998 & 128 & $11: 07$ & 128 & $14: 59$ \\
1998 & 129 & $02: 47$ & 129 & $06: 31$ \\
1998 & 151 & $02: 47$ & 151 & $06: 55$ \\
1998 & 151 & $22: 15$ & 152 & $05: 11$ \\
1998 & 155 & $01: 25$ & 155 & $04: 59$ \\
1998 & 234 & $16: 41$ & 234 & $20: 15$ \\
1998 & 235 & $14: 27$ & 235 & $18: 53$ \\
1998 & 241 & $22: 15$ & 242 & $05: 59$ \\
1998 & 245 & $22: 15$ & 246 & $02: 31$ \\
1998 & 249 & $13: 55$ & 249 & $23: 35$ \\
1998 & 254 & $15: 17$ & 254 & $21: 13$ \\
1998 & 261 & $03: 47$ & 261 & $11: 33$ \\
1999 & 136 & $01: 25$ & 136 & $09: 17$ \\
1999 & 143 & $13: 55$ & 144 & $01: 15$ \\
\hline
\end{tabular}

\subsection{Time delay}

In order to relate the magnetopause observations made by a GIT spacecraft to the upstream observations made by Wind, it is necessary to estimate the time delay between the spacecraft: that is, the time interval between a phase front encountering Wind, and the same phase front subsequently encountering the GIT spacecraft. In this study, the time delay is calculated for each data point in the following manner.

First, an initial estimate of time delay is calculated by dividing the distance between Wind and GIT at each time-step in the GIT data by the mean value of the X-component of the solar wind velocity during the interval. For each GIT timestep, the time delay is subtracted from the GIT time, and the Wind data point closest to that time is determined. Then an array is constructed of time-shifted Wind data points corresponding to the unshifted GIT data points.

Significant changes in the solar wind velocity, such as occur at the bow shock, would introduce a systematic offset into this initial estimate. In order to take account of this offset, two further steps are taken. First, the cross-correlation function $(\mathrm{CCF})$ of the GIT clock angle and the time-shifted Wind clock angle are calculated over the entire interval. The Wind data are then further shifted by the lag which maximises the CCF.

Finally, the Wind and spacecraft clock angles are overlaid on a plot (bottom panel, Fig. 1, and visually inspected. If necessary, an additional time-shift was introduced in order to improve the match between the clock angles when the spacecraft is well out in the sheath. This was done in about a quarter of cases, typically by less than $5 \mathrm{~min}$.
Table 2. Magnetopause-crossing intervals from the Geotail spacecraft.

\begin{tabular}{ccccc}
\multicolumn{5}{c}{ Geotail } \\
\hline year & start day & $\begin{array}{c}\text { start time } \\
\text { (UT) }\end{array}$ & end day & $\begin{array}{c}\text { end time } \\
\text { (UT) }\end{array}$ \\
\hline 1998 & 110 & $05: 33$ & 110 & $07: 09$ \\
1998 & 115 & $08: 20$ & 115 & $10: 19$ \\
1998 & 120 & $11: 07$ & 120 & $13: 40$ \\
1999 & 124 & $04: 10$ & 124 & $09: 56$ \\
1999 & 134 & $12: 30$ & 134 & $16: 47$ \\
1998 & 136 & $01: 23$ & 136 & $05: 32$ \\
1998 & 145 & $05: 34$ & 145 & $08: 52$ \\
1998 & 146 & $13: 54$ & 146 & $16: 12$ \\
1998 & 150 & $11: 06$ & 150 & $15: 48$ \\
1998 & 151 & $22: 14$ & 152 & $11: 00$ \\
1998 & 234 & $01: 23$ & 234 & $03: 36$ \\
1998 & 244 & $02: 47$ & 244 & $12: 29$ \\
1998 & 249 & $08: 20$ & 249 & $15: 49$ \\
1998 & 260 & $23: 37$ & 261 & $06: 58$ \\
1998 & 327 & $11: 08$ & 327 & $17: 13$ \\
1998 & 363 & $16: 40$ & 363 & $23: 53$ \\
1999 & 113 & $16: 40$ & 114 & $01: 42$ \\
1999 & 118 & $19: 27$ & 119 & $02: 50$ \\
1999 & 301 & $09: 44$ & 301 & $14: 25$ \\
\hline
\end{tabular}

\subsection{Scaling to standard model}

In order to build up an aggregate picture of draping, all the GIT spacecraft boundary crossing position data are scaled such that the crossing fits a standard magnetopause. In this paper, the magnetopause used is the Tsyganenko 96 (T96) ellipsoidal magnetopause, which scales in a self-similar fashion according to the solar wind pressure (Tsyganenko, 1995). For the reference magnetopause, a pressure of $2.0 \mathrm{nPa}$ is used, close to the long-term solar wind average, giving a subsolar magnetopause distance of $11.08 R_{E}$.

The model position of the T96 magnetopause is set by the solar wind pressure. However, this position does not always correspond to the true magnetopause location (Ober et al., 2000; Pinnock et al., 2002). Accordingly, the measured solar wind pressure is not used in this paper to set the model boundary. Rather, this boundary is found by iteratively adjusting the pressure parameter in the T96 model until the model magnetopause includes the spacecraft position at the time of boundary crossing.

Once the model magnetopause has been fitted to the observed boundary crossing, the dimensionless ellipsoidal coordinates of the GIT spacecraft trajectory are calculated in the pressure-adjusted model, using the formulae in Tsyganenko (1995). From these, the cartesian coordinates of the spacecraft trajectory in the unadjusted, reference model are calculated. These are the scaled coordinates, which are used in the analysis in Sects. 3 and 4. 

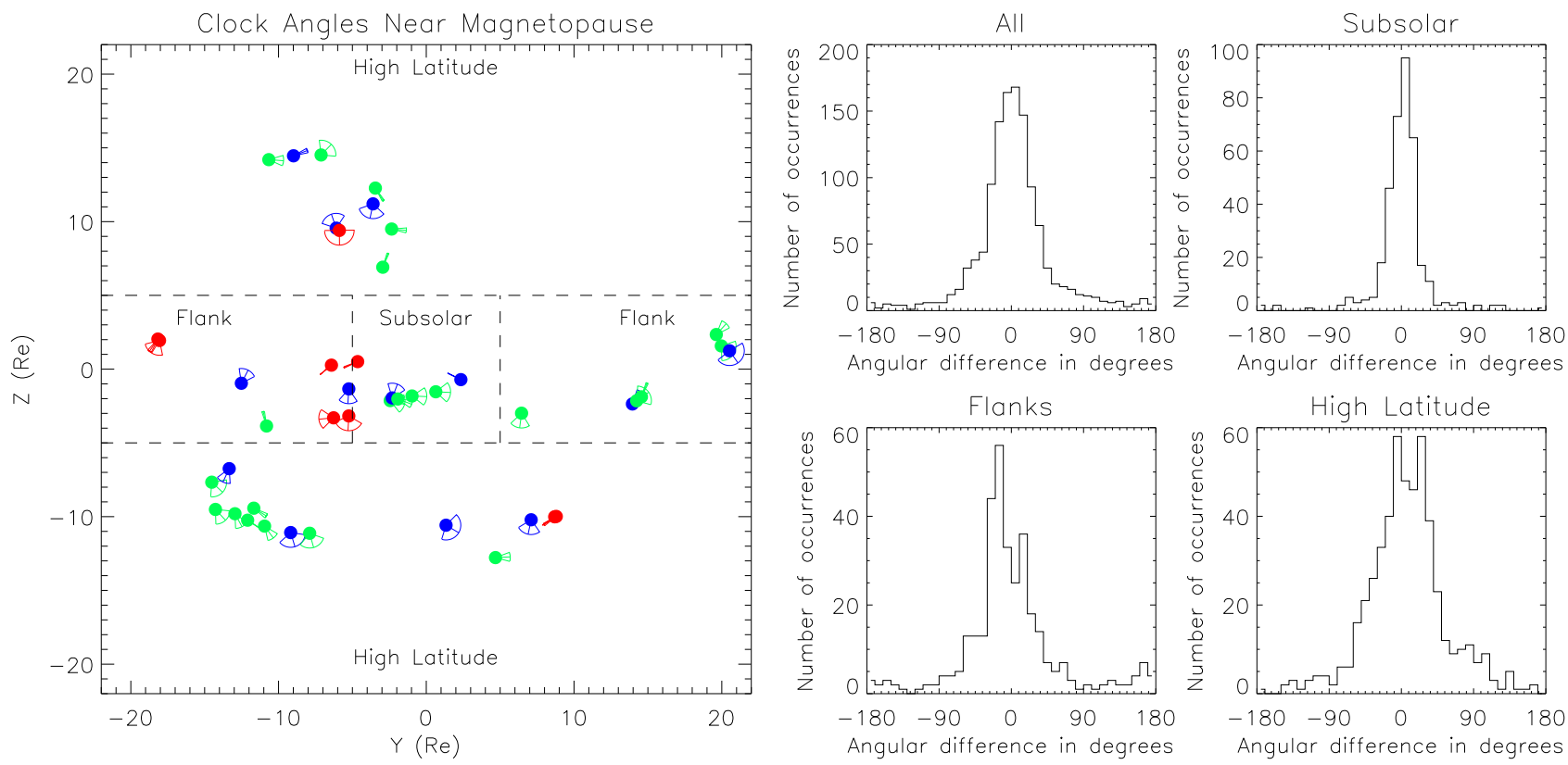

Fig. 2. Clock angles measured near magnetopause, and angular differences from perfect draping, for unsmoothed data. The mean position of the data points (in GSM coordinates) within each $2 R_{E}$ bin is shown as a filled circle, and the mean clock angle is indicated by a line. The standard deviation of the clock angles within each bin is indicated by an arc of total angular extent equal to twice the standard deviation. The colour coding indicates the difference between the mean clock angle measured near the magnetopause, and that observed in the corresponding upstream IMF data: green for a difference of less than $30^{\circ}$, blue for a difference between $30^{\circ}$ and $90^{\circ}$, and red where the difference is greater than $90^{\circ}$. The histograms show the distribution of angular differences over the entire magnetopause ("All"), and the subsolar, flank, and high latitude regions. The extent of these regions is shown on the magnetopause plot.

\section{Data integration}

Once the scaling to a standard magnetopause has been performed, data files for each crossing interval are created. These comprise the scaled GIT magnetosheath-crossing data (namely spacecraft position, magnetic field clock angle and magnetic field cone angle for each time step) and the corresponding, time-shifted Wind data (namely the magnetic field clock angle and cone angle for each time step). GSM coordinates are used throughout, with the Wind data converted into the GSM frame appropriate for the corresponding GIT data points.

For the main analysis, the data files for each GIT magnetopause crossing are concatenated into one combined data file. Also, all files where solar wind pressure is $>2 \mathrm{nPa}$ are concatenated into a high-pressure file, and where pressure $\leq 2 \mathrm{nPa}$ into a low-pressure file.

This entire procedure is then repeated, with the additional step of smoothing the magnetic field data. The magnetic field clock angle and cone angle time series, for both the Wind spacecraft and the GIT magnetopause-crossing spacecraft, are smoothed with a boxcar filter. This is done for a filter width of five minutes (the analysis was also performed using a ten-minute filter, with essentially identical results). A standard boxcar filter would simply calculate the mean of the data points contained within the filter width. This is not appropriate when smoothing angles, because of the mathe- matical properties of angles. For example, the mean of 179 and -179 is zero, but a time series which fluctuates between $179^{\circ}$ and $-179^{\circ}$ ought to be smoothed out to $180^{\circ}$ or, equivalently, $-180^{\circ}$. The smoothing algorithm used here accomplishes this by computing the mean and standard deviation of the relevant angles twice: once for the angles in the range $\left[-180^{\circ}, 180^{\circ}\right]$, and once for the same angles in the range $\left[0^{\circ}\right.$, $360^{\circ}$ ]. The standard deviations in these two cases are compared. Whichever case gives the lower standard deviation is the case whose mean is used in the analysis.

\subsection{Sorting, binning and presentation}

The data are spatially binned and averaged to produce plots with a standard format, like that of Fig. 2. The left-hand panel shows the dayside magnetosheath projected in the $\mathrm{y}-\mathrm{z}$ plane, and is divided into grid squares of side $2 R_{E}$. For all data points lying within a given grid square, the mean angle and position are calculated and plotted: the position is marked by a filled circle, and the angle is indicated by a line. Note that the mean position is not, in general, the centre of the grid square. The standard deviation is shown as an arc segment: the arc subtends an angle of twice the standard deviation, centered on the mean angle. The angular difference from perfect draping is shown by the colour coding: green for a small difference $\left(\leq 30^{\circ}\right)$, blue for a moderate difference $\left(>30^{\circ}\right.$ and $\left.\leq 90^{\circ}\right)$, and red for a large difference $\left(>90^{\circ}\right)$. 
Table 3. Distribution of absolute angular differences between the clock angle of the magnetosheath field measured within $2 R_{E}$ of the magnetopause and the time-shifted IMF clock angle. The subsolar region is defined by $|y|<5 R_{E}$ and $|z|<5 R_{E}$, the high-latitude regions, defined by $|z| \geq 5 R_{E}$, and the equatorial flanks, defined by $|y| \geq 5 R_{E}$ and $|z|<5 R_{E} . \mathrm{N}$ is the total number of points in the magnetopausecrossing data. The mean and standard deviation of the angular difference are shown in the columns "mean" and "s.d.", and the last six columns show the percentage of data points in each of six ranges of angular difference.

\begin{tabular}{lrrrrrrrrr}
\hline Region & $\mathrm{N}$ & mean & s.d. & $0-10^{\circ}$ & $10-20^{\circ}$ & $20-30^{\circ}$ & $30-60^{\circ}$ & $60-90^{\circ}$ & $90-180^{\circ}$ \\
\hline All & 1221 & 2.93 & 48.36 & 27.19 & 23.67 & 15.40 & 18.84 & 6.55 & 8.35 \\
Subsolar & 366 & 1.12 & 32.58 & 45.90 & 30.33 & 9.56 & 7.65 & 3.28 & 3.28 \\
Flanks & 344 & -0.81 & 60.07 & 16.86 & 26.74 & 18.02 & 18.90 & 6.98 & 12.50 \\
High Lat & 511 & 6.75 & 48.81 & 20.74 & 16.83 & 17.81 & 26.81 & 8.61 & 9.20 \\
\hline
\end{tabular}

Table 4. Distribution of angular differences, for data subject to 5-min boxcar smoothing. Format as in Table 3.

\begin{tabular}{lrrrrrrrrr}
\hline Region & $\mathrm{N}$ & mean & s.d. & $0-10^{\circ}$ & $10-20^{\circ}$ & $20-30^{\circ}$ & $30-60^{\circ}$ & $60-90^{\circ}$ & $90-180^{\circ}$ \\
\hline All & 1222 & 3.92 & 44.46 & 30.44 & 23.24 & 16.37 & 17.35 & 5.81 & 6.79 \\
Subsolar & 363 & 3.57 & 25.93 & 50.96 & 31.40 & 9.64 & 3.58 & 1.93 & 2.48 \\
Flanks & 342 & -0.32 & 55.44 & 19.30 & 23.10 & 20.76 & 20.47 & 6.73 & 9.65 \\
High Lat & 517 & 6.96 & 46.40 & 23.40 & 17.60 & 18.18 & 24.95 & 7.93 & 7.93 \\
\hline
\end{tabular}

Table 5. Distribution of angular differences in the Northward IMF case (IMF clock angle between $-15^{\circ}$ and $15^{\circ}$ ). Format as in Table 3 .

\begin{tabular}{lrrrrrrrrr}
\hline Region & $\mathrm{N}$ & mean & s.d. & $0-10^{\circ}$ & $10-20^{\circ}$ & $20-30^{\circ}$ & $30-60^{\circ}$ & $60-90^{\circ}$ & $90-180^{\circ}$ \\
\hline All & 147 & -7.89 & 65.11 & 12.24 & 15.65 & 26.53 & 12.93 & 14.29 & 18.37 \\
Subsolar & 16 & 21.74 & 43.64 & 31.25 & 18.75 & 18.75 & 12.50 & 12.50 & 6.25 \\
Flanks & 79 & -18.47 & 61.59 & 7.59 & 24.05 & 43.04 & 3.80 & 1.27 & 20.25 \\
High Lat & 52 & -0.93 & 72.64 & 13.46 & 1.92 & 3.85 & 26.92 & 34.62 & 19.23 \\
\hline
\end{tabular}

Table 6. Distribution of angular differences in the Southward IMF case (IMF clock angle between $-165^{\circ}$ and $165^{\circ}$ ). Format as in Table 3 .

\begin{tabular}{lrrrrrrrrr}
\hline Region & $\mathrm{N}$ & mean & s.d. & $0-10^{\circ}$ & $10-20^{\circ}$ & $20-30^{\circ}$ & $30-60^{\circ}$ & $60-90^{\circ}$ & $90-180^{\circ}$ \\
\hline All & 221 & 6.46 & 32.76 & 29.41 & 23.08 & 16.74 & 24.43 & 4.52 & 1.81 \\
Subsolar & 4 & 40.10 & 34.82 & 0.00 & 25.00 & 0.00 & 50.00 & 25.00 & 0.00 \\
Flanks & 95 & 13.78 & 30.84 & 38.95 & 21.05 & 13.68 & 17.89 & 5.26 & 3.16 \\
High Lat & 122 & -0.34 & 32.49 & 22.95 & 24.59 & 19.67 & 28.69 & 3.28 & 0.82 \\
\hline
\end{tabular}

Table 7. Distribution of angular differences in the $B_{y}$ positive case (IMF clock angle between $45^{\circ}$ and $135^{\circ}$ ). Format as in Table 3 .

\begin{tabular}{lrrrrrrrrr}
\hline Region & $\mathrm{N}$ & mean & s.d. & $0-10^{\circ}$ & $10-20^{\circ}$ & $20-30^{\circ}$ & $30-60^{\circ}$ & $60-90^{\circ}$ & $90-180^{\circ}$ \\
\hline All & 769 & 2.10 & 38.27 & 32.12 & 24.97 & 16.25 & 18.08 & 4.16 & 4.42 \\
Subsolar & 312 & 2.98 & 23.97 & 52.24 & 32.37 & 8.97 & 3.21 & 0.96 & 2.24 \\
Flanks & 163 & -7.44 & 53.57 & 11.04 & 22.70 & 21.47 & 28.22 & 8.59 & 7.98 \\
High Lat & 294 & 6.44 & 39.66 & 22.45 & 18.37 & 21.09 & 28.23 & 5.10 & 4.76 \\
\hline
\end{tabular}

Another view of the data is given in histogram form in the right-hand panels. Here, the data are sorted by the clock angle deviation - that is, the difference between the clock angle measured by the magnetopause-crossing spacecraft and that measured upstream by the Wind spacecraft - and binned into ten-degree intervals. In addition to the histogram for the whole magnetopause, three other histograms are shown for the data spatially sorted into three magnetopause regions: The subsolar region, defined by $|y|<5 R_{E}$ and $|z|<5 R_{E}$, the high-latitude regions, defined by $|z| \geq 5 R_{E}$, and the equatorial flanks, defined by $|y| \geq 5 R_{E}$ and $|z|<5 R_{E}$. 

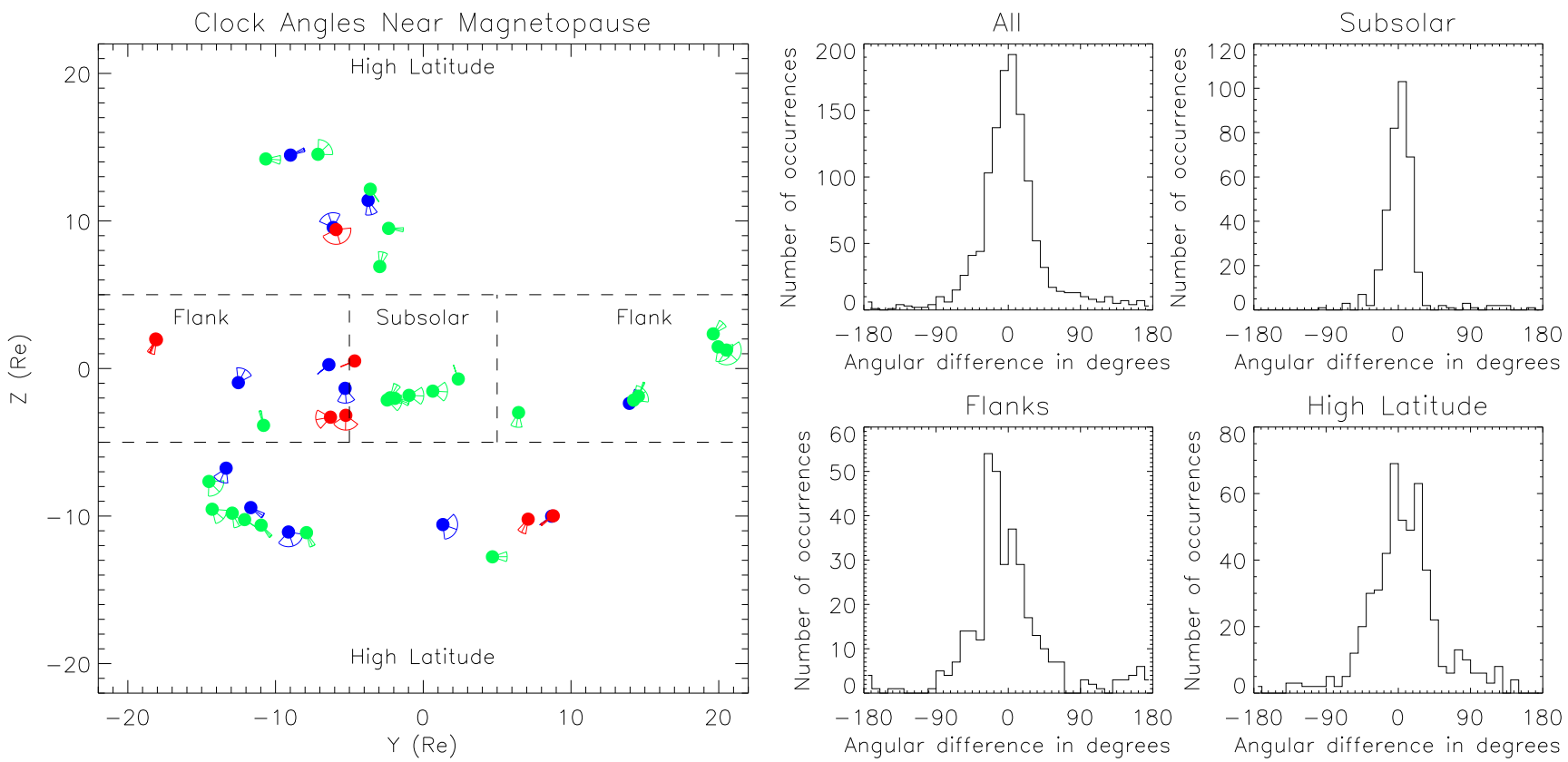

Fig. 3. Clock angles measured near magnetopause, and angular differences from perfect draping, for smoothed data (five-minute boxcar filter). Format as Fig. 2.
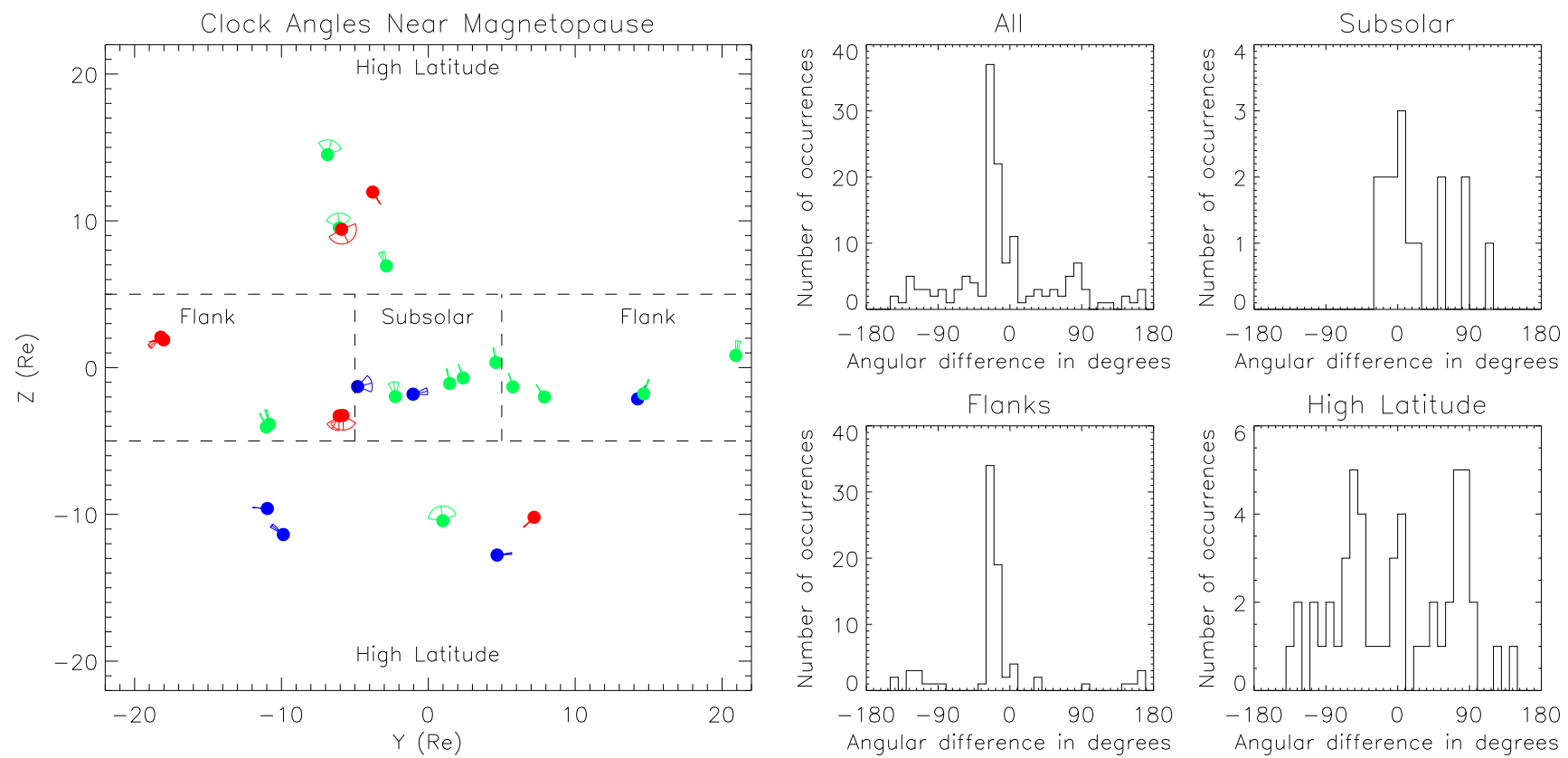

Fig. 4. Clock angles measured near magnetopause, and angular differences from perfect draping, for Northward IMF. Format as Fig. 2.

\section{Results}

The first set of results are for data which has been filtered only for distance from the magnetopause: All data points in the magnetosheath whose scaled position is less than $2 R_{E}$ from the reference model magnetopause are retained, and all other data points are discarded. The analysis is performed for unsmoothed data (Fig. 2 and Table 3), and for data which has been smoothed with a five-minute boxcar filter (Fig. 3 and Table 4), as described above.

For the unsmoothed data, $27 \%$ are within $10^{\circ}$ of perfect draping, $51 \%$ are within $20^{\circ}, 66 \%$ are within $30^{\circ}, 85 \%$ within $60^{\circ}$ and $92 \%$ are within $90^{\circ}$. When the data are smoothed, $30 \%$ of the data points are within $10^{\circ}$ of perfect draping, $54 \%$ are within $20^{\circ}, 70 \%$ are within $30^{\circ}, 87 \%$ within $60^{\circ}$ and $93 \%$ are within $90^{\circ}$. Smoothing appears to 

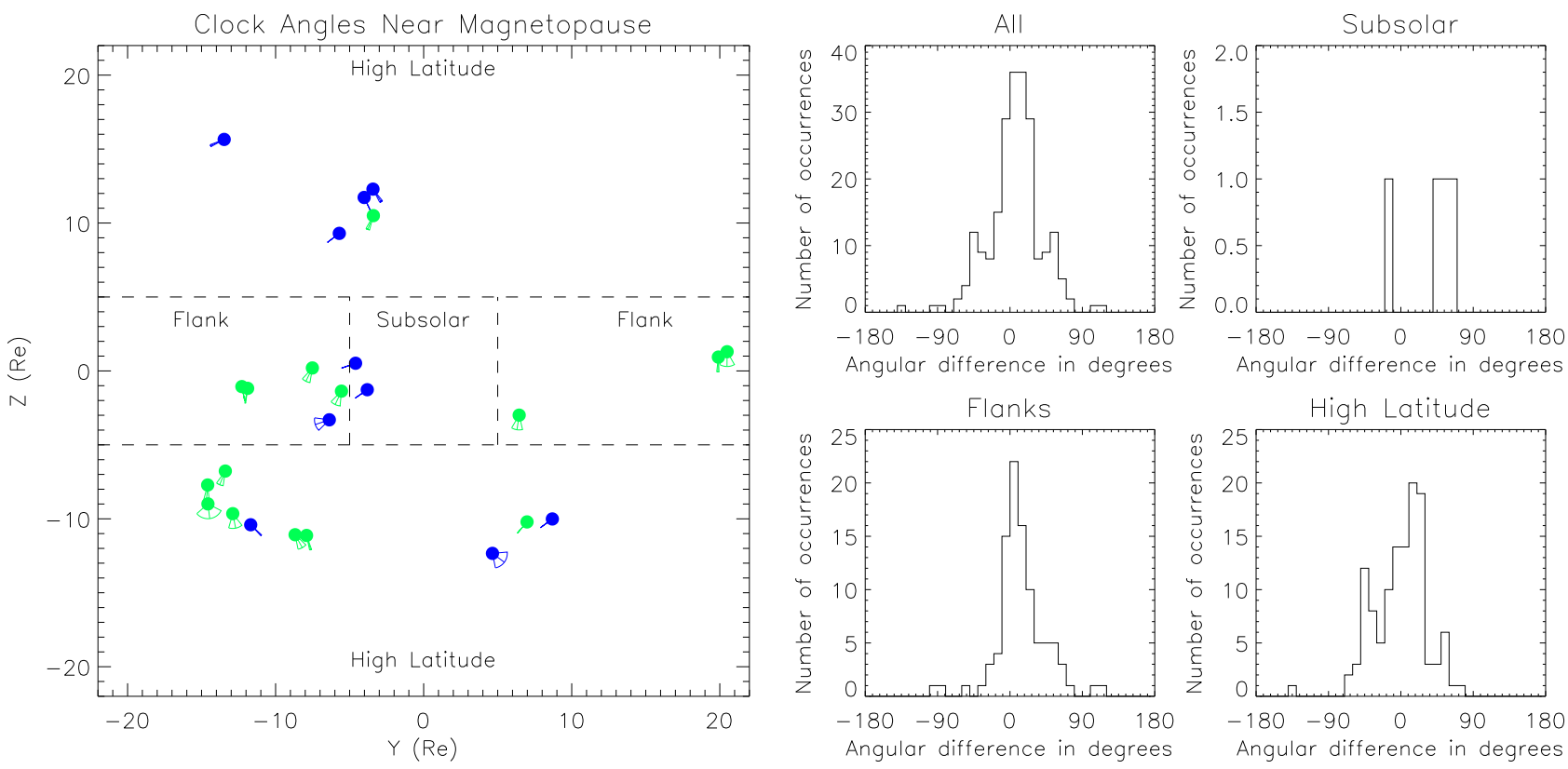

Fig. 5. Clock angles measured near magnetopause, and angular differences from perfect draping, for Southward IMF. Format as Figure 2.
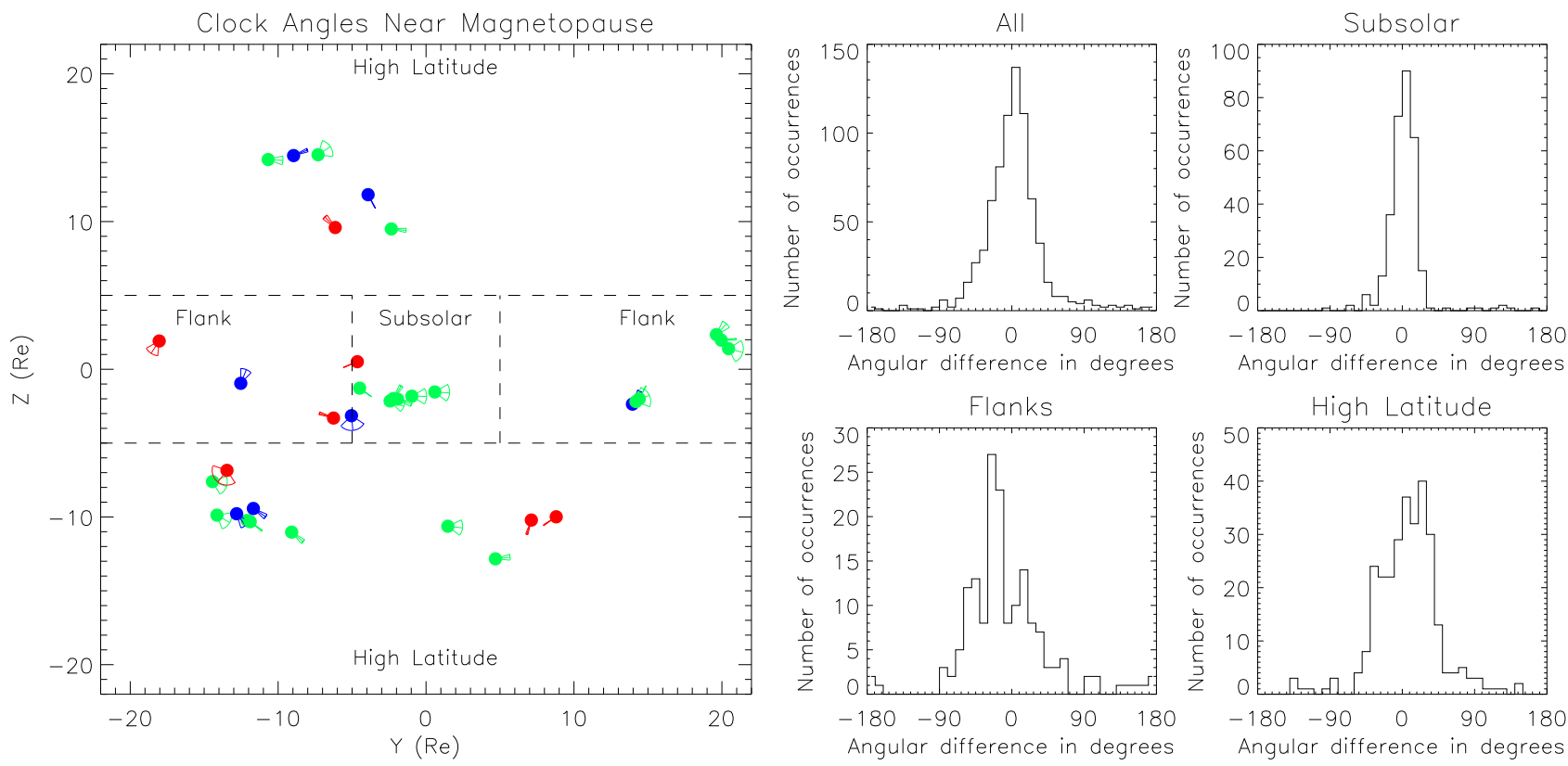

Fig. 6. Clock angles measured near magnetopause, and angular differences from perfect draping, for IMF with $B_{y}$ positive. Format as Fig. 2 .

improve the fit to perfect draping by a few percent. However, a Kolmogorov-Smirnov test shows that there is no significant difference at the $95 \%$ level between the smoothed and the unsmoothed data sets. The smoothed data sets are used throughout the remainder of this paper.

There are clear differences between the magnetopause regions. The equatorial flanks have the smallest mean difference from perfect draping, but the largest standard deviation, while the largest mean difference is at high latitudes, and the least variability can be seen in the subsolar region. Note in particular that, in the subsolar region, more than $50 \%$ of data points are within $10^{\circ}$ of perfect draping (for the smoothed data set). This fraction drops to $23.4 \%$ in the high latitude regions, and $19.3 \%$ in the flanks. 

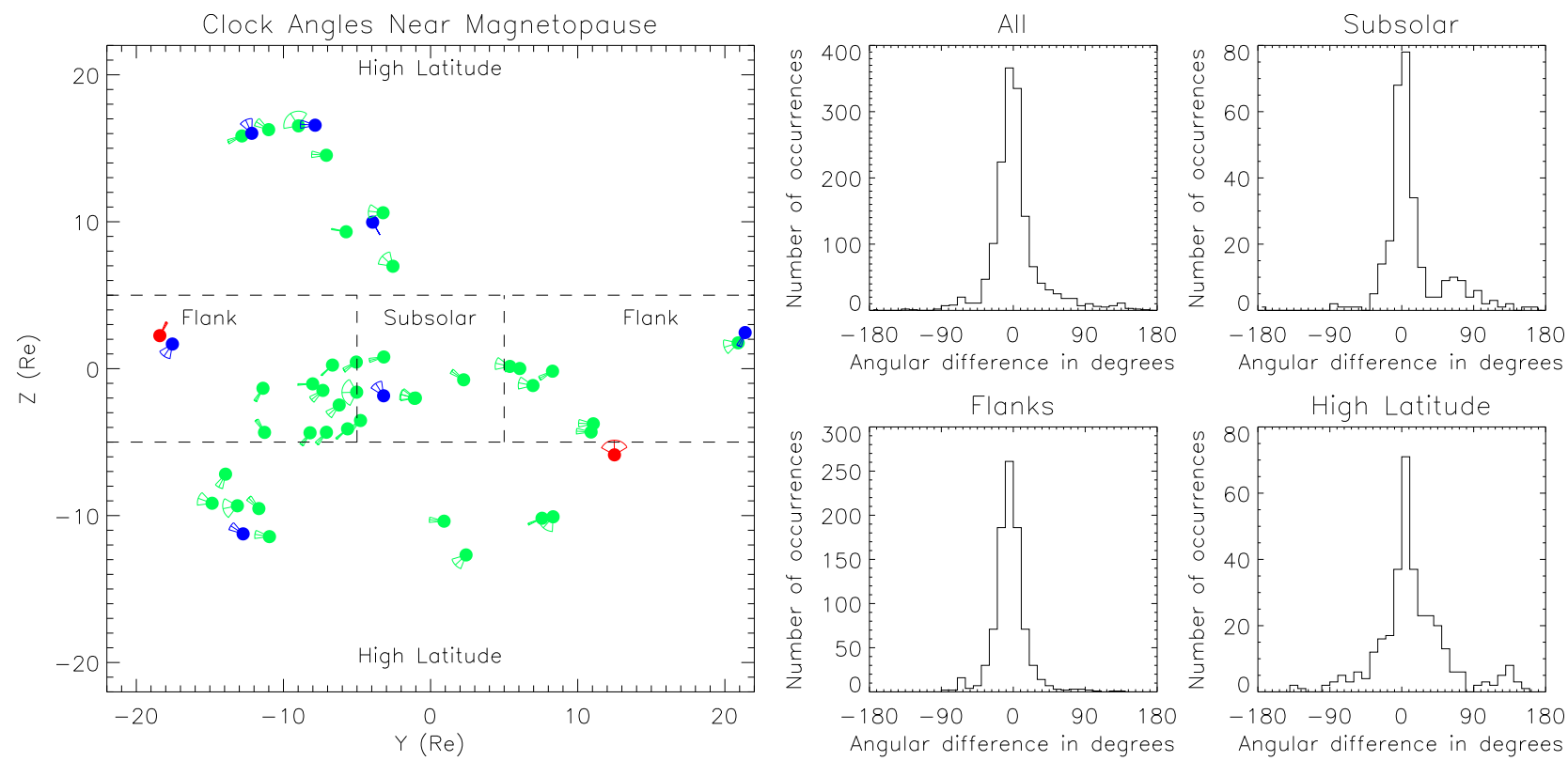

Fig. 7. Clock angles measured near magnetopause, and angular differences from perfect draping, for IMF with $B_{y}$ negative. Format as Fig. 2.
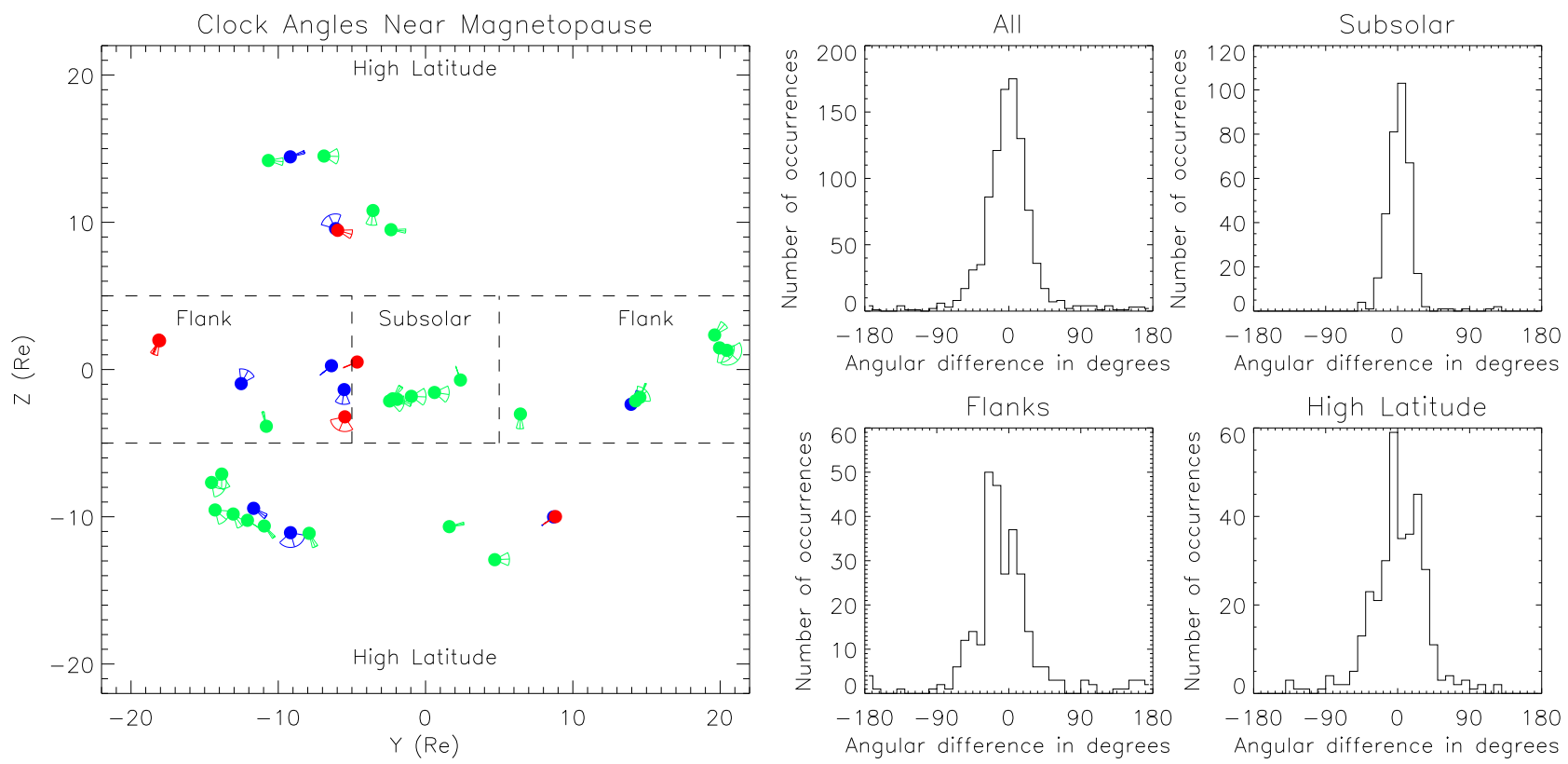

Fig. 8. Clock angles measured near magnetopause, and angular differences from perfect draping, for restricted IMF cone angle. Format as Fig. 2.

\subsection{Northward IMF}

Figure 4 and Table 5 show the results for draping near the magnetopause when the IMF is northward. In addition to filtering for distance from the magnetopause (as in the previous case), the data are also filtered so that only data points corresponding to a clock angle measured by the Wind spacecraft less than $15^{\circ}$ and greater than $-15^{\circ}$ are retained.
With smoothing as above, the standard deviation of the angular difference is lowest at the subsolar point $\left(43.64^{\circ}\right)$, highest at high latitudes $\left(72.64^{\circ}\right)$, and intermediate on the flanks $\left(61.59^{\circ}\right)$. The strikingly high variability at high latitudes may be due to enhanced flow irregularities in the cusp entry layer (Haerendel et al., 1978) 
Table 8. Distribution of angular differences in the $B y$ negative case (IMF clock angle between $-135^{\circ}$ and $-45^{\circ}$ ). Format as in Table 3 .

\begin{tabular}{lrrrrrrrrr}
\hline Region & $\mathrm{N}$ & mean & s.d. & $0-10^{\circ}$ & $10-20^{\circ}$ & $20-30^{\circ}$ & $30-60^{\circ}$ & $60-90^{\circ}$ & $90-180^{\circ}$ \\
\hline All & 1529 & 2.92 & 32.83 & 45.85 & 23.94 & 10.92 & 10.86 & 5.10 & 3.34 \\
Subsolar & 295 & 13.05 & 37.89 & 49.49 & 18.64 & 9.15 & 7.80 & 9.15 & 5.76 \\
Flanks & 903 & -4.30 & 21.36 & 49.50 & 28.46 & 11.18 & 7.20 & 3.10 & 0.55 \\
High Lat & 331 & 13.60 & 46.02 & 32.63 & 16.31 & 11.78 & 23.56 & 6.95 & 8.76 \\
\hline
\end{tabular}

Table 9. Distribution of angular differences, filtered for IMF cone angle between $45^{\circ}$ and $135^{\circ}$. Format as in Table 3 .

\begin{tabular}{lrrrrrrrrr}
\hline Region & $\mathrm{N}$ & mean & s.d. & $0-10^{\circ}$ & $10-20^{\circ}$ & $20-30^{\circ}$ & $30-60^{\circ}$ & $60-90^{\circ}$ & $90-180^{\circ}$ \\
\hline All & 965 & -0.25 & 36.09 & 35.44 & 26.01 & 16.79 & 14.82 & 3.21 & 3.73 \\
Subsolar & 340 & 2.84 & 18.21 & 54.12 & 32.65 & 9.41 & 2.35 & 0.59 & 0.88 \\
Flanks & 288 & -5.66 & 48.91 & 22.22 & 25.69 & 22.22 & 18.06 & 4.17 & 7.64 \\
High Lat & 337 & 1.26 & 36.36 & 27.89 & 19.58 & 19.58 & 24.63 & 5.04 & 3.26 \\
\hline
\end{tabular}

Table 10. Distribution of angular differences in the high pressure case (solar wind dynamic pressure $>2 \mathrm{nPa}$ ). Format as in Table 3 .

\begin{tabular}{lrrrrrrrrr}
\hline Region & $\mathrm{N}$ & mean & s.d. & $0-10^{\circ}$ & $10-20^{\circ}$ & $20-30^{\circ}$ & $30-60^{\circ}$ & $60-90^{\circ}$ & $90-180^{\circ}$ \\
\hline All & 641 & -0.53 & 50.86 & 28.71 & 26.05 & 14.51 & 13.88 & 7.64 & 9.20 \\
Subsolar & 162 & 5.75 & 34.61 & 43.83 & 35.80 & 7.41 & 3.70 & 4.32 & 4.94 \\
Flanks & 342 & -0.32 & 55.44 & 19.30 & 23.10 & 20.76 & 20.47 & 6.73 & 9.65 \\
High Lat & 137 & -8.49 & 54.18 & 34.31 & 21.90 & 7.30 & 9.49 & 13.87 & 13.14 \\
\hline
\end{tabular}

Table 11. Distribution of angular differences in the low pressure case (solar wind dynamic pressure $\leq 2 \mathrm{nPa}$ ). Format as in Table 3 .

\begin{tabular}{lrrrrrrrrr}
\hline Region & $\mathrm{N}$ & mean & s.d. & $0-10^{\circ}$ & $10-20^{\circ}$ & $20-30^{\circ}$ & $30-60^{\circ}$ & $60-90^{\circ}$ & $90-180^{\circ}$ \\
\hline All & 581 & 8.83 & 35.51 & 32.36 & 20.14 & 18.42 & 21.17 & 3.79 & 4.13 \\
Subsolar & 201 & 1.81 & 15.68 & 56.72 & 27.86 & 11.44 & 3.48 & 0.00 & 0.50 \\
Flanks & 0 & 0.00 & 0.00 & 0.00 & 0.00 & 0.00 & 0.00 & 0.00 & 0.00 \\
High Lat & 380 & 12.53 & 41.95 & 19.47 & 16.05 & 22.11 & 30.53 & 5.79 & 6.05 \\
\hline
\end{tabular}

\subsection{Southward IMF}

As in the previous case, the data set here is limited to those points within $2 R_{E}$ of the model magnetopause surface. The data is further filtered so as to only include data points which correspond to a clock angle measured by the Wind spacecraft of greater than $165^{\circ}$ or less than $-165^{\circ}$. Figure 5 and Table 6 show the results.

Here, there are very few (only 4) data points from the subsolar region. The standard deviation in this region is $34.82^{\circ}$. The flanks have a similar standard deviation to that in the high latitude areas, despite having a greater percentage of points within $10^{\circ}$ of perfect draping. This is because the flanks also have a larger number of angular differences greater than $60^{\circ}$. Compared to the northward case, all regions show substantially lower standard deviations, and the magnitude of the mean difference is less in all regions except the subsolar. It might be expected that the flank regions would show greater differences in the southward case, as an equatorial reconnection region stretching along the flanks and through the subsolar point may increase disturbances in these regions of the magnetosheath. Reconnection scenarios in which the $\mathrm{x}$-line is moved away from the equatorial flanks due to the IMF $B_{y}$ component or the effect of the Earth's dipole tilt may go some way towards explaining this observation. It is difficult to draw firm conclusions about the subsolar region, due to the small number of data points.

A Kolmogorov-Smirnov test shows that the difference between the northward IMF and southward IMF data sets is significant, at the $95 \%$ level. Even without such a test, it is clear from the magnetopause plots that the magnetic field direction is broadly northward over most of the magnetopause when the IMF is northward, and broadly southward when the IMF is southward. This is consistent with the wellestablished role played by the z-component of the IMF in driving the magnetosphere-ionosphere system (Cowley and Lockwood (1992) and references therein), as a southward (northward) IMF yields a broadly southward (northward) magnetosheath field which gives rise to a greater (lesser) 

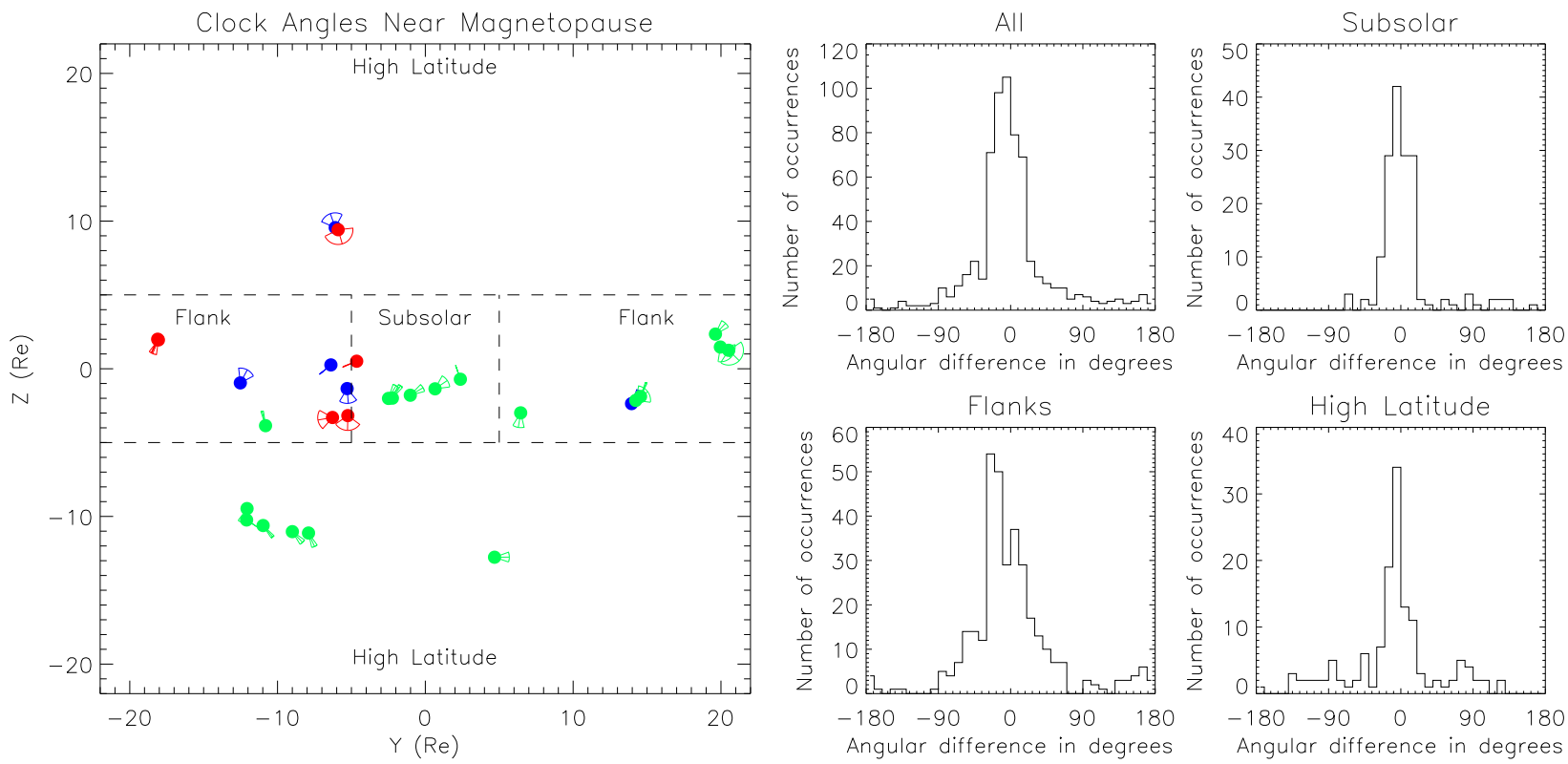

Fig. 9. Clock angles measured near magnetopause, and angular differences from perfect draping, for high solar wind dynamic pressure. Format as Fig. 2.
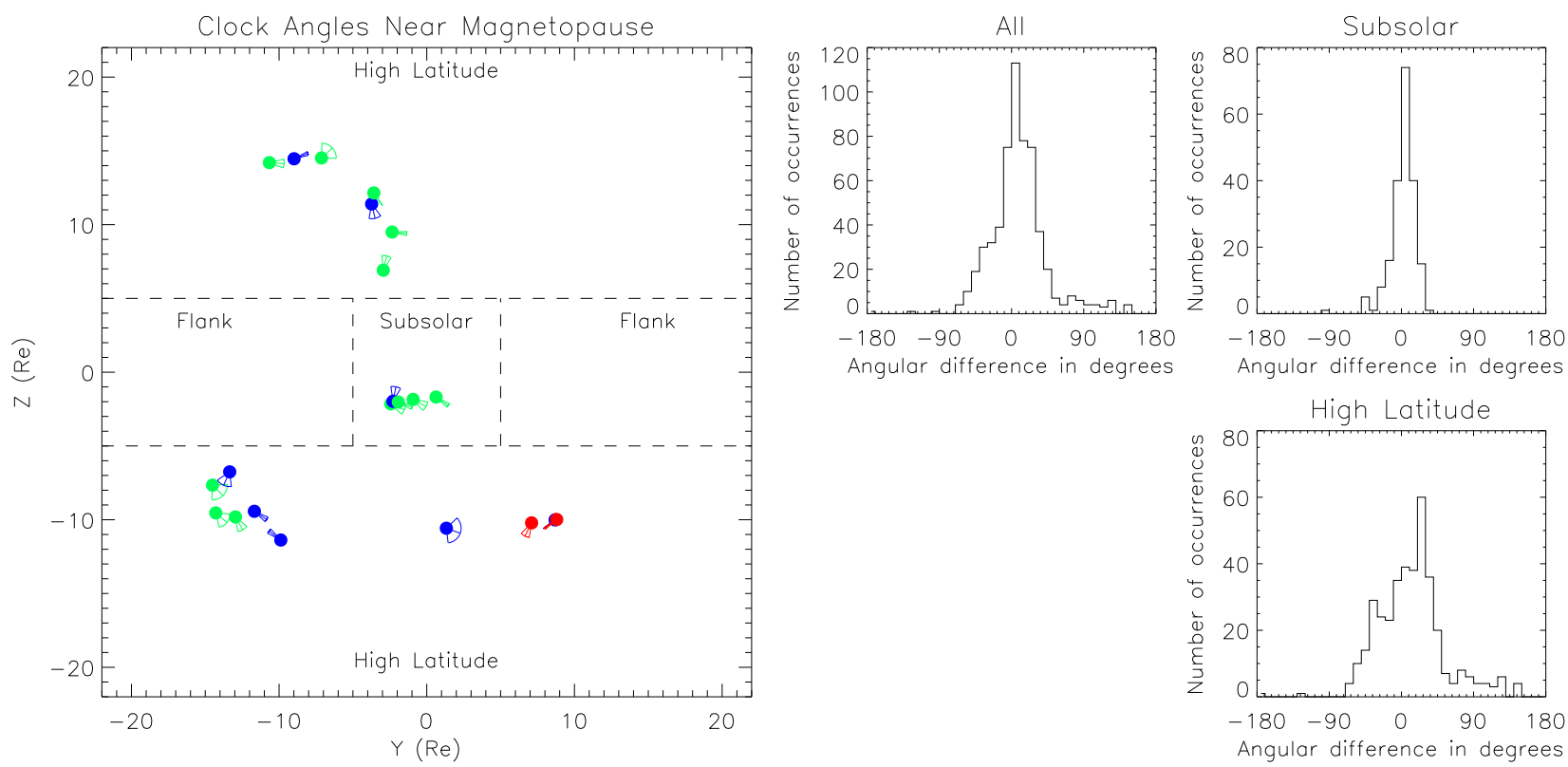

Fig. 10. Clock angles measured near magnetopause, and angular differences from perfect draping, for low solar wind dynamic pressure. Format as Fig. 2.

reconnection rate. Thus, the mechanism which gives rise to the correlation between IMF clock angle and reconnection rates measured in the ionosphere is confirmed by this study. However, the large proportion of substantial differences from perfect draping indicate that this global relationship between the IMF and the magnetic field which drives the magnetosphere does not necessarily translate to a local correspondence in time and space between the IMF direction and that of the magnetosheath field.

\section{$4.3 \quad B_{y}$ filtering}

Tables 7 and 8, and Figs. 6 and 7, show the results of filtering the data to pick out $B_{y}$-dominated IMF orientations. For the positive $B_{y}$ case, the data were restricted to cases where the clock angle was between $45^{\circ}$ and $135^{\circ}$ : For negative $B_{y}$, where the clock angle was between $-135^{\circ}$ and $-45^{\circ}$. There are significant differences between the two cases. At the flanks and at high latitudes, the distributions of angular 

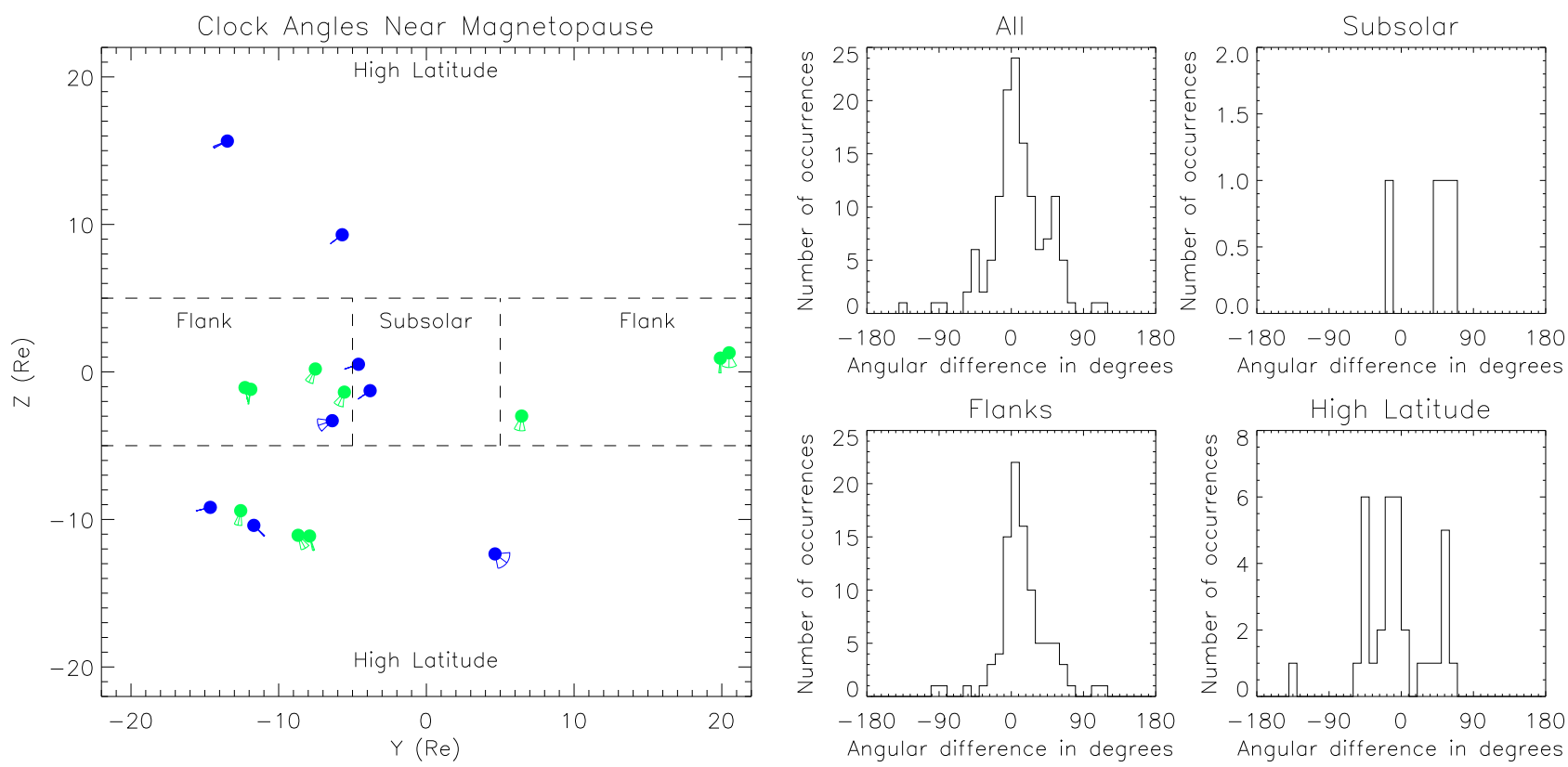

Fig. 11. Clock angles measured near magnetopause, and angular differences from perfect draping, for high solar wind dynamic pressure and Southward IMF. Format as Fig. 2.
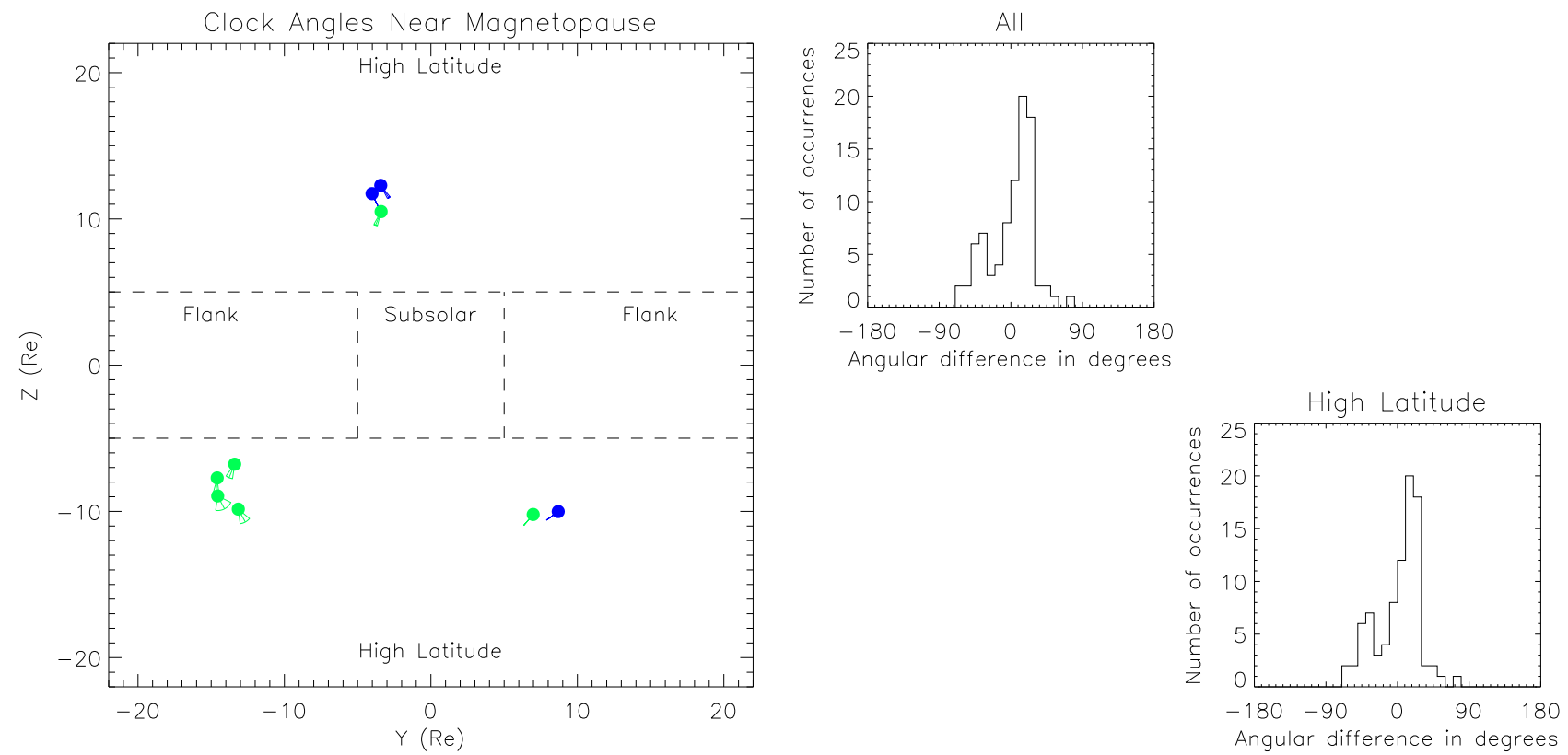

Fig. 12. Clock angles measured near magnetopause, and angular differences from perfect draping, for low solar wind dynamic pressure and Southward IMF. Format as Fig. 2.

differences are much broader in the positive $B_{y}$ case. At the flanks, this is coupled with a higher standard deviation: This is not the case at high latitudes, because the distribution in this region in the negative $B_{y}$ case has a high-end tail at large positive angular differences.

As in the case of northward and southward IMF, there is a broad similarity between the IMF direction and the clock angles shown in the magnetopause plots, but substantial lo- cal divergences from perfect draping. What is different in this case is that the clock angles at high latitudes appear to follow a systematic pattern in many cases. For example, in the vicinity of $Y=-10 R_{E}, Z=-10 R_{E}$, in both the positive and negative $B_{y}$ cases, the magnetic field directions are roughly aligned along an arc. This suggests an ordered draping effect, in which the magnetic field lines are distorted so as to approximately follow the shape of the magnetopause 

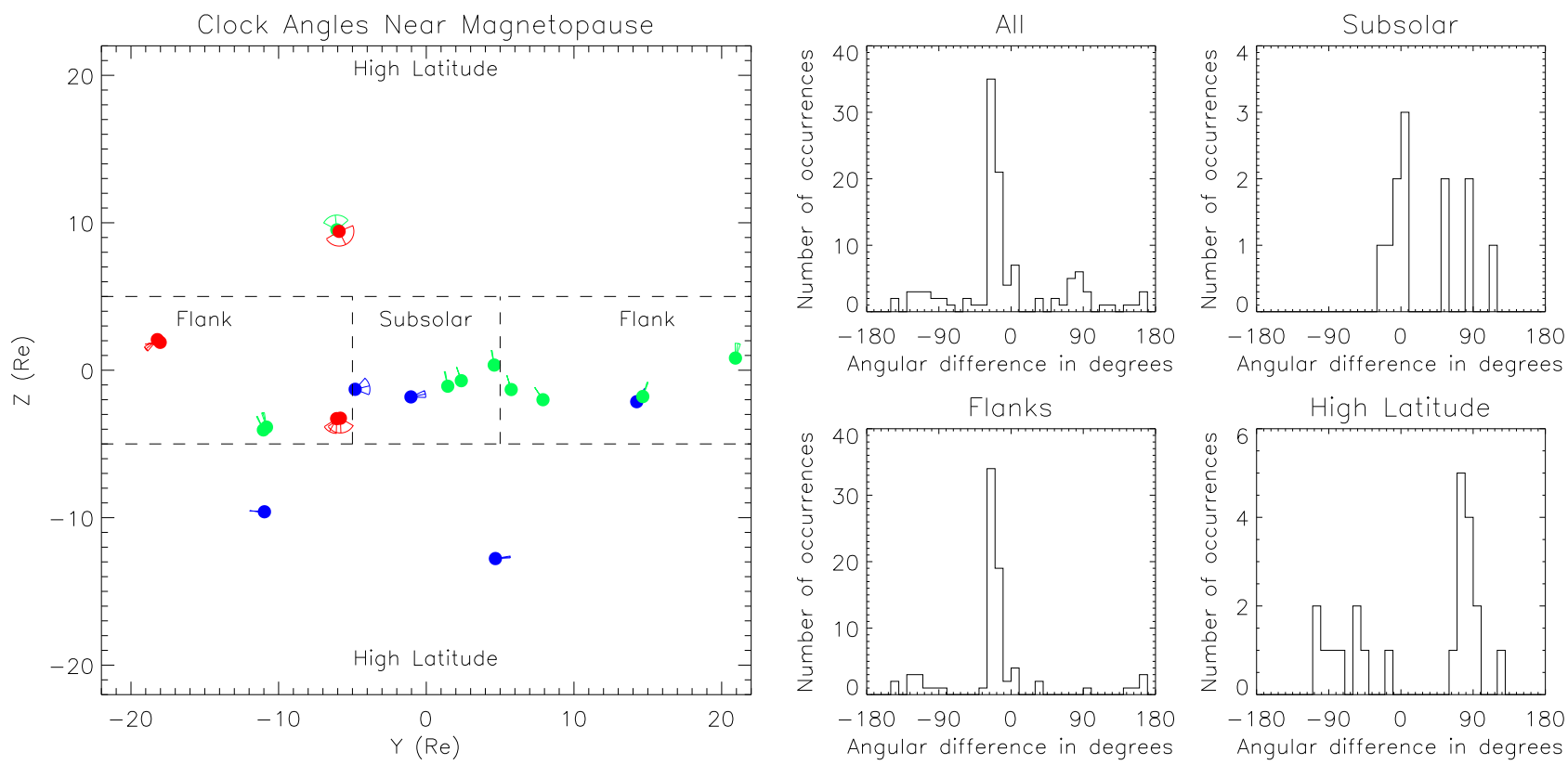

Fig. 13. Clock angles measured near magnetopause, and angular differences from perfect draping, for high solar wind dynamic pressure and Northward IMF. Format as Fig. 2.
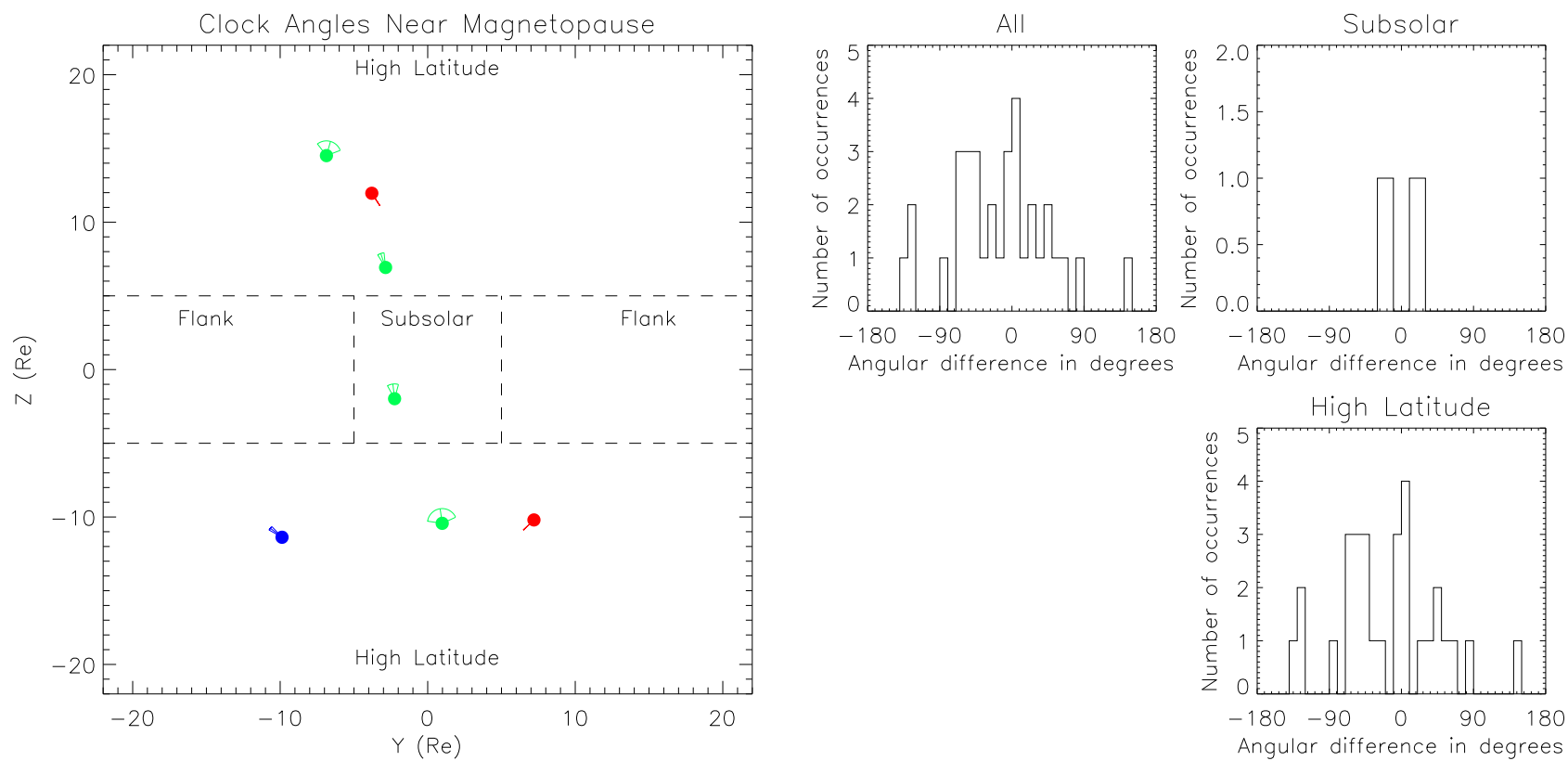

Fig. 14. Clock angles measured near magnetopause, and angular differences from perfect draping, for low solar wind dynamic pressure and Northward IMF. Format as Fig. 2.

boundary. This effect disappears at lower latitudes, and is absent for other IMF orientations, and so a systematic draping effect seems to be the exception, rather than the rule.

\subsection{Cone angle filtering}

The previous analysis has not considered what influence the cone angle of the IMF might have on the magnetic field drap- ing. Figure 8 and Table 9 show the results of repeating the analysis of section 4 for all IMF clock angles, but with the restriction that the cone angle is in the range $45^{\circ}$ to $135^{\circ}$ (i.e. within $45^{\circ}$ of being exactly perpendicular to the $\mathrm{x}$-axis). This cone angle filtering makes the draping closer to perfect, in that the standard deviation is less than it is without cone angle filtering, and the magnitude of the mean angular difference is smaller in all regions except the equatorial flanks. 
Table 12. Distribution of angular differences in the high pressure case (solar wind dynamic pressure $>2 \mathrm{nPa}$ ) for Southward IMF (IMF clock angle between $-165^{\circ}$ and $165^{\circ}$ ). Format as in Table 3 .

\begin{tabular}{lrrrrrrrrr}
\hline Region & $\mathrm{N}$ & mean & s.d. & $0-10^{\circ}$ & $10-20^{\circ}$ & $20-30^{\circ}$ & $30-60^{\circ}$ & $60-90^{\circ}$ & $90-180^{\circ}$ \\
\hline All & 133 & 9.51 & 35.31 & 33.83 & 20.30 & 12.03 & 25.56 & 5.26 & 3.01 \\
Subsolar & 4 & 40.10 & 34.82 & 0.00 & 25.00 & 0.00 & 50.00 & 25.00 & 0.00 \\
Flanks & 95 & 13.78 & 30.84 & 38.95 & 21.05 & 13.68 & 17.89 & 5.26 & 3.16 \\
High Lat & 34 & -6.01 & 41.90 & 23.53 & 17.65 & 8.82 & 44.12 & 2.94 & 2.94 \\
\hline
\end{tabular}

Table 13. Distribution of angular differences in the low pressure case (solar wind dynamic pressure $\leq 2 \mathrm{nPa}$ ) for Southward IMF (IMF clock angle between $-165^{\circ}$ and $165^{\circ}$ ). Format as in Table 3

\begin{tabular}{lrrrrrrrrr}
\hline Region & $\mathrm{N}$ & mean & s.d. & $0-10^{\circ}$ & $10-20^{\circ}$ & $20-30^{\circ}$ & $30-60^{\circ}$ & $60-90^{\circ}$ & $90-180^{\circ}$ \\
\hline All & 88 & 1.85 & 28.02 & 22.73 & 27.27 & 23.86 & 22.73 & 3.41 & 0.00 \\
Subsolar & 0 & 0.00 & 0.00 & 0.00 & 0.00 & 0.00 & 0.00 & 0.00 & 0.00 \\
Flanks & 0 & 0.00 & 0.00 & 0.00 & 0.00 & 0.00 & 0.00 & 0.00 & 0.00 \\
High Lat & 88 & 1.85 & 28.02 & 22.73 & 27.27 & 23.86 & 22.73 & 3.41 & 0.00 \\
\hline
\end{tabular}

Table 14. Distribution of angular differences in the high pressure case (solar wind dynamic pressure $>2 \mathrm{nPa}$ ) for Northward IMF (IMF clock angle between $-15^{\circ}$ and $15^{\circ}$ ). Format as in Table 3 .

\begin{tabular}{lrrrrrrrrr}
\hline Region & $\mathrm{N}$ & mean & s.d. & $0-10^{\circ}$ & $10-20^{\circ}$ & $20-30^{\circ}$ & $30-60^{\circ}$ & $60-90^{\circ}$ & $90-180^{\circ}$ \\
\hline All & 113 & -5.64 & 66.76 & 9.73 & 18.58 & 30.97 & 7.08 & 13.27 & 20.35 \\
Subsolar & 12 & 29.09 & 46.73 & 41.67 & 8.33 & 8.33 & 16.67 & 16.67 & 8.33 \\
Flanks & 79 & -18.47 & 61.59 & 7.59 & 24.05 & 43.04 & 3.80 & 1.27 & 20.25 \\
High Lat & 22 & 21.52 & 80.32 & 0.00 & 4.55 & 0.00 & 13.64 & 54.55 & 27.27 \\
\hline
\end{tabular}

Table 15. Distribution of angular differences in the low pressure case (solar wind dynamic pressure $\leq 2 \mathrm{nPa}$ ) for Northward IMF (IMF clock angle between $-15^{\circ}$ and $15^{\circ}$ ). Format as in Table 3 .

\begin{tabular}{lrrrrrrrrr}
\hline Region & $\mathrm{N}$ & mean & s.d. & $0-10^{\circ}$ & $10-20^{\circ}$ & $20-30^{\circ}$ & $30-60^{\circ}$ & $60-90^{\circ}$ & $90-180^{\circ}$ \\
\hline All & 34 & -15.38 & 59.65 & 20.59 & 5.88 & 11.76 & 32.35 & 17.65 & 11.76 \\
Subsolar & 4 & -0.33 & 25.54 & 0.00 & 50.00 & 50.00 & 0.00 & 0.00 & 0.00 \\
Flanks & 0 & 0.00 & 0.00 & 0.00 & 0.00 & 0.00 & 0.00 & 0.00 & 0.00 \\
High Lat & 30 & -17.38 & 62.82 & 23.33 & 0.00 & 6.67 & 36.67 & 20.00 & 13.33 \\
\hline
\end{tabular}

These differences are significant at the $95 \%$ level, and may reflect a physical dependency of the draping process on the angle between the magnetic field and velocity field vectors in the oncoming plasma.

This same cone angle filtering has also been applied to the restricted data sets of Northward and Southward IMF respectively, see Sects. 4.1 and 4.2 for definitions of these data sets.) In both cases, the differences between the results with cone angle filtering and the results without it are not significant.

\subsection{Pressure filtering}

As described in Sect. 3, the data were divided into two subsets, corresponding to high and low solar wind pressure. The analyses of Sects. 4, 4.1 and 4.2 were performed on both these data subsets. The results are shown in Figs. 9 to 14, and Tables 10 to 15 . In general, the high pressure case exhibits lower angular differences from perfect draping.

Without filtering by clock angle, the distributions of angular difference are clearly different in the high and low pressure cases. The main source of this pressure-related difference is in the form of the distribution of angular differences in the high-latitude regions, with the low-pressure case having a much broader and less symmetrical distribution than the high-pressure case. A Kolmogorov-Smirnov test shows that the differences in these distributions are significant (at the $95 \%$ level). Unfortunately, filtering by pressure removes all the flank data points from the low-pressure data set, so it is not possible to determine the effects of solar wind pressure on magnetosheath draping in the equatorial flanks. 
There is also a significant difference between the high and low pressure cases when the data are restricted to southward IMF (as defined in Sect. 4.2). This conclusion only applies to the high latitude region, however, as this is the only region for which data fitting the IMF and pressure criteria exists. When the same analysis is performed for northward IMF (as defined in Sect. 4.1), no significant difference is found between the high and low pressure data sets.

\section{Conclusions}

Overall, only about $30 \%$ of data points exhibit perfect draping within $\pm 10^{\circ}$, and only $70 \%$ are within $30^{\circ}$. Removing cone angles which are more than $45^{\circ}$ from perpendicular improves the perfect draping fit, by preferentially filtering out the most extreme angular differences. Southward IMF data are closer to perfect draping than northward IMF data: This is particularly marked in the high-latitude regions, probably due to cusp effects. Magnetosheath draping is not symmetric with respect to $B_{y}$ : The angular deviations at the flanks and at high latitudes are distributed very differently when $B_{y}$ is positive than when $B_{y}$ is negative.

Some of the deviations from perfect draping, particularly in the high-latitude flanks, roughly follow the magnetopause shape. These can be understood in terms of gas-dynamic draping at the magnetopause surfaces. Most angular differences, however, are not so well-ordered, and perfect draping is generally a better approximation than gas-dynamic draping, in which the magnetopause shape gives rise to systematic deviations from perfect draping which are not seen in most of the data presented in this paper. Thus it is not a safe assumption, particularly when considering regions far from the subsolar point, to generally assume that the magnetosheath field is related to the upstream IMF in some fairly simple, regular fashion.

There are three possible sources for this complex behaviour: Structure in the solar wind, disorder introduced by the transition from the solar wind to the magnetopause, and complex phenomena at the magnetopause surface. There is no reason to expect the effects of solar wind structure to vary according to magnetopause location or IMF orientation, so this cannot explain all the variability seen in this study. In addition, the time delay calculations of Sect. 2.2 involved matching the GIT clock angle measured far from the magnetopause crossing with the upstream clock angle observed by Wind: The relative closeness of this match, compared to that seen near the magnetopause, further suggests that phenomena near the magnetopause are an important contributor to the variability. Highly structured flows, including turbulent flows, near the magnetopause, are one plausible candidate. This is likely to be particularly important in the high-latitude regions, as discussed in Sect. 4.1. Other possibilities include departures of the magnetospheric field from the static, quasi-dipolar field of the Tsyganenko 96 model. Waves on the magnetopause surface, such as Kelvin-Helmholtz waves, may result in departures from perfect draping, particularly in the equatorial flank regions, while magnetic reconnection and the consequent motion of flux tubes across the magnetopause can create a disordered magnetic field structure over any part of the magnetopause, particularly for southward IMF. In general, the magnetosphere is open and always reconnecting (Lyons et al., 1994), so any oncoming IMF phase front will typically encounter a reconnecting magnetopause rather than a quasi-dipole. The effects of these surface phenomena on the magnetosheath field immediately upstream, close to the magnetopause, are not clear. Nevertheless, interactions between the magnetosheath plasma and a complex, structured magnetopause may play a part in producing the highly variable draping behaviour shown in this paper.

The main question in this paper is this: Given an upstream measurement of the IMF orientation, what can we say about the orientation of the magnetosheath field close to the magnetopause? It is safe to assume that a southward IMF usually leads to a generally southward magnetosheath field, and similarly for northward, eastward or westward IMF. That is, the average IMF and magnetosheath clock angles are similar when averaged over a sufficiently large spatial scale. It is not safe to rely on the orientation of the magnetosheath field at any given patch within $2 R_{E}$ of the dayside magnetopause on 5 -min averaged timescales being similar to that observed in the upstream IMF, or to that predicted by any simple gasdynamic or analytical model.

These results are important for models of reconnection in which the magnetosheath magnetic field orientation plays a significant role and, in particular, suggest that a greater understanding of the spatio-temporal structuring of the solar wind and magnetosheath, and consideration of its effects, are needed.

Acknowledgements. The WIND satellite data were provided by the NASA/GSFC CDAWeb, and the author thanks R. Lepping, A. Lazarus, and K. Ogilvie, for making them available. The Geotail magnetic field and plasma data were provided by S. Kokubun, and T. Mukai, through DARTS at the Institute of Space and Astronautical Science (ISAS) in Japan, and the Interball-Tail data by S. Romanov, and J.-A. Sauvaud The author would like to thank M. Pinnock, M. Freeman and M. Lester for useful discussions of this work.

Topical Editor T. Pulkkinen thanks M. Goldstein and Z. Kaymaz for their help in evaluating this paper.

\section{References}

Coleman, I. J., Pinnock, M., and Rodger, A. S.: The ionospheric footprint of antiparallel merging regions on the dayside magnetopause, Ann. Geophys., 18, 511-516, 2000,

SRef-ID: 1432-0576/ag/2000-18-511.

Coleman, I. J., Chisham, G., Pinnock, M., and Freeman, M. P.: An ionospheric convection signature of antiparallel reconnection, J. Geophys. Res., 106, 28 995-29 007, 2001.

Cooling, B. M. A., Owen, C. J., and Schwartz, S. J.: Role of magnetosheath flow in determining the motion of open flux tubes, $\mathbf{J}$ Geophys. Res., 106, 18 763-18 775, 2001.

Cowley, S. W. H. and Lockwood, M.: Excitation and decay of solar wind-driven flows in the magnetosphere-ionosphere system, Ann. Geophys., 10, 103-115, 1992. 
Crooker, N. U.: Dayside merging and cusp geometry, J. Geophys. Res., 84, 951-959, 1979.

Dungey, J. W.: Interplanetary magnetic field and the auroral zone, Phys. Rev. Lett., 6, 47-49, 1961.

Dunlop, M. W., Balogh, A., Baumjohann, W., Haerendel, G., Fornacon, K.-H., and Georgescu, E.: Dawnside magnetopause observed by the Equator-S Magnetic Field Experiment: Identification and survey of crossings, J. Geophys. Res., 104, 17491$17497,1999$.

Frank, L. A., Anderson, K. L., Paterson, W. R., Lee, J. A., English, M. R., and Pickett, G. L.: The Comprehensive Plasma Instrumentation (CPI) for the Geotail Spacecraft, J. Geomag. and Geoelectr., 46, 23-37, 1994.

Haerendel, G., Paschmann, G., Sckopke, N., Rosenbauer, H., and Hedgecock, P. C.: The frontside boundary layer of the magnetosphere and the problem of reconnection, J. Geophys. Res., 83, 3195-3216, 1978.

Hapgood, M. A. and Bryant, D. A.: Exploring the magnetospheric boundary layer, Planet. Space Sci., 40, 1431-1459, 1992.

Kaymaz, Z., Siscoe, G. L., and Luhmann, J. G.: IMF draping around the geotail: IMP 8 observations, J. Geophys. Res., 19, 829-832, 1992

Kaymaz, Z., Siscoe, G. L., Luhmann, J. G., Fedder, J. A., and Lyon, J. G.: Interplanetary field control of magnetotail field: IMP 8 data and MHD model compared, J. Geophys. Res., 100, $17163-$ 17 172, 1995.

Kaymaz, Z.: IMP 8 magnetosheath field comparisons with models, Ann. Geophys., 16, 376-387, 1998,

SRef-ID: 1432-0576/ag/1998-16-376.

Klimov, S., Romanov, S., Amata, E., Blecki, J., Buechner, J., Juchniewicz, J., Rustenbach, J., Triska, P., Woolliscroft, L. J. C., Savin, S., Afanas'yev, Y., de Angelis, U., Auster, U., Bellucci, G., Best, A., Farnik, F., Formisano, V., Gough, P., Grard, R., Grushin, V., Haerendel, G., Ivchenko, V., Korepanov, V., Lehmann, H., Nikutowski, B., Nozdrachev, M., Orsini, S., Parrot, M., Rauch, J. L., Petrukovich, A., Sauer, K., Skalsky, A., Slominski, J., Trotignon, J. G., Vojta, J., and Wronowski, R.: APSI experiment: measurements of fields and waves on board the INTERBALL-TAIL mission, Ann. Geophys., 15, 514-527, 1997 ,

\section{SRef-ID: 1432-0576/ag/1997-15-514.}

Kobel, E. and Flückiger, E. O.: A model of the steady state magnetic field in the magnetosheath, J. Geophys. Res., 99, 23 617-23 622, 1994.

Kokubun, S., Yamamoto, T., Acuna, M. H., Hayashi, K., Shiokawa, K., and Kawano, H.: The Geotail magnetic field experiment, J. Geomag. Geoelectr., 46, 7-21, 1994.

Lepping, R. P., Acuna, M., Burlaga, L., Farrell, W., Slavin, J., Schatten, K., Mariani, F., Ness, N., Neubauer, F., Whang, Y. C., Byrnes, J., Kennon, R., Panetta, P., Scheifele. J., and Worley, E.: The WIND magnetic field investigation, Space Sci. Rev., 71, 207-229, 1995.
Luhmann, J. G., Walker, R. J., Russell, C. T., Crooker, N. U., Spreiter, J. R., and Stahara, S. S.: Patterns of potential magnetic field merging sites on the dayside magnetopause, J. Geophys. Res., 89, 1739-1742, 1984.

Lyons, L. R., Schulz, M., Pridmore-Brown, D. C., and Roeder, J. L.: Low-latitude boundary layer near noon: An open field line model, J. Geophys. Res., 99, 17 367-17 377, 1994.

Ober, D. M., Maynard, N. C., Burke, W. J., Moen, J., Egeland, A., Sandholt, P. E., Farrugia, C. J., Weber, E. J., and Scudder, J. D.: Mapping prenoon auroral structures to the magnetosphere, J. Geophys. Res., 105, 27 519-27 530, 2000.

Ogilvie, K. W., Chorney, D. J., Fitzenreiter, R. J., Hunsaker, F., Keller, J., Lobell, J., Miller, G., Scudder, J. D., Sittler, Jr., E. C., Torbert, R. B., Bodet, D., Needell, G., Lazarus, A. J., Steinberg, J. T., Tappan, J. H., Mavretic, A., and Gergin, E.: SWE, a comprehensive plasma instrument for the Wind spacecraft, Space Sci. Rev., 71, 55-77, 1995.

Petrinec, S. M., Mukai, T., Nishida, A., Yamamoto, T., Nakamura, T. K., and Kokubun, S.: Geotail observations of magnetosheath flow near the magnetopause, using Wind as a solar monitor, J. Geophys. Res., 102, 26 943-26 959, 1997.

Pinnock, M., Chisham, G., Coleman, I. J., Freeman, M. P., and Hairston, M,: The location and rate of dayside reconnection during an interval of southward IMF, Ann. Geophys., 21, 14671482, 2003,

SRef-ID: 1432-0576/ag/2003-21-1467.

Rodger, A. S., Coleman, I. J., and Pinnock, M.: Some comments on transient and steady-state reconnection at the dayside magnetopause, J. Geophys. Res., 27, 1359-1362, 2000.

Sauvaud, J-A., Barthe, H., Aostin, C., Thocaven, J. J., Rouzaud, J., Bouyssou, J., Cassignol, M., Souleille, P., Bosqued, J. M., Beutier, T., Crasnier, J., Dandouras, J., Jacquey, C., and Réme, H.: The electron experiment: a top-hat spectrometer for the tail probe, in INTERBALL mission and payload Ed. RKA, IKI and CHES, Toulouse, 153-169, 1995.

Sonnerup, B. O. U.: Magnetopause reconnection rate: J. Geophys. Res., 79, 1546-1549, 1974.

Spreiter, J. R., Summers, A. L., and Alksne, A. Y.: Hydromagnetic flow around the magnetosphere, Planet. Space Sci., 14, 223-253, 1966.

Tsyganenko, N. A.: Modeling the Earth's magnetospheric magnetic field confined within a realistic magnetopause: J. Geophys. Res., 100, 5599-5612, 1995.

Zhang, X. X., Song, P., Stahara, S. S., Spreiter, J. R., Russell, C. T., and Le, G.: Large scale structures in the magnetosheath: Exogenous or endogenous in origin?, J. Geophys. Res., 23, 105-108, 1996. 